Article

\title{
Experiences of Dynamic Identification and Monitoring of Bridges in Serviceability Conditions and after Hazardous Events
}

\author{
Carlo Rainieri ${ }^{1, * \mathbb{D}}$, Matilde A. Notarangelo ${ }^{2}$ and Giovanni Fabbrocino ${ }^{3,4}(\mathbb{C}$ \\ 1 Construction Technologies Institute-Secondary Branch of Naples, National Research Council of Italy, \\ 80146 Naples, Italy \\ 2 S2X s.r.l., 86100 Campobasso, Italy; matilde.notarangelo@s2x.it \\ 3 DiBT Department, StreGa Lab, University of Molise, 86100 Campobasso, Italy; \\ giovanni.fabbrocino@unimol.it \\ 4 Construction Technologies Institute-Secondary Branch of L'Aquila, National Research Council of Italy, \\ 67100 L'Aquila, Italy \\ * Correspondence: rainieri@itc.cnr.it
}

Received: 17 September 2020; Accepted: 12 October 2020; Published: 16 October 2020

\begin{abstract}
Operational Modal Analysis (OMA) currently represents an appealing technique for the non-destructive assessment and health monitoring of civil structures and infrastructures. Many applications have appeared in the literature in the last decade, demonstrating how this technique can support the observation and understanding of the structural behavior of bridges at different stages of their lifecycle and the remote detection of structural damage. The present paper describes some explanatory applications of OMA and modal-based Structural Health Monitoring (SHM) referring to bridges that have been carried out by the authors over the years. Some aspects related to the evolution of OMA in the last decade are summarized by means of the presentation and discussion of a number of case studies; they cover the fields of the non-destructive assessment and monitoring of bridges in serviceability conditions as well after hazardous events and remark the potential and the opportunities of OMA in the modern management of road infrastructures.
\end{abstract}

Keywords: bridges; operational modal analysis; structural health monitoring; vibration; model validation

\section{Introduction}

Operational Modal Analysis (OMA) [1] has been a very active field of research over the last two decades, also thanks to the developments in sensing technologies enabling the accurate measure of the very low amplitude response induced in large civil structures, such as bridges, by ambient excitation. Large research efforts have been also spent to increase the reliability and accuracy of the experimental estimates of modal parameters, yielding theoretical and algorithmic developments as well as refined testing procedures [2-4]. Over the years, several applications of OMA to bridges concerned the validation and/or updating of numerical models at the commissioning stage as well as after retrofitting interventions. For instance, a modal analysis under operational conditions has been used to validate the modeling assumptions and characterize the baseline condition of the structural behavior [5], and to support the structural assessment before and after strengthening works aimed at increasing vehicle traffic and axle loads on a highway bridge [6], in combination with model updating procedures. OMA has been also successfully applied to analyze the dynamic response of footbridges, whose design criteria-lighter loads - and architectural features make them slender and, as such, prone to problems related to the serviceability limit state of vibration. One of the challenges in structural design is the 
vibration control under the dynamic loads associated with pedestrian walking and/or running and allotting the frequency bandwidth of the structure far from the one associated to the pace frequency of the users. To this aim, an experimental analysis of the dynamic response of the real bridge is one of the key steps of the testing before the commissioning of the infrastructure [7]. An illustrative application of OMA to the assessment of the dynamic behavior of a footbridge is illustrated in [8]. The numerical model of the footbridge was updated, and it was used to support the design of a set of tuned mass dampers to control the amplitude of vibrations [9]. In [10] the vibration serviceability of eight footbridges is assessed, at completion and after model updating, based on simplified load models to simulate a pedestrian-induced input. The study highlighted how the adopted load models were sensitive to small changes in the natural frequencies, thus jeopardizing the reliability of the design. Some attempts of using OMA and model updating for damage assessment of bridges are also reported in the literature [11,12]. In these cases, the numerical model of the structure is updated in the healthy and in the damaged states, so that the comparison between the two models guides the identification of damage location. The use of OMA and model updating to assess the sensitivity of modal parameters in terms of increasing scour-induced settlements is instead discussed in [13], remarking the potential of OMA-based strategies for scour monitoring and early warning. The successful applications of OMA and model updating to bridges recently motivated the Italian Ministry of Transportation to recommend their application in the analysis of existing bridges in order to reduce modeling uncertainties and support the structural maintenance and design of strengthening interventions [14]. Following the progress in the data acquisition, processing, and transmission technologies, OMA techniques have been further developed to fit the requirements of permanent dynamic monitoring and remote damage detection in the field of the civil structures and infrastructures. In more detail, the development of several automated OMA techniques (see, for instance, $[15,16]$ and the references therein) has raised the interest towards the applications of dynamic identification and continuous monitoring in civil engineering. Many existing bridges are indeed subjected to traffic loadings larger than those considered in the design stage, resulting in the acceleration of fatigue problems and reduction in the service life [17]. Besides, the detection of damage and degradation phenomena is still based on visual inspections and this may yield inconsistent results due to the different experience and capacity of bridge inspectors, or leave undetected the damage at unreachable locations, affecting the overall safety. Modal-based Structural Health Monitoring (SHM) systems can be therefore exploited for timely damage detection and maintenance support, thus shifting from the current reactive or scheduled approaches to a proactive one with the related benefits in terms of life cycle costs and down-time reduction. The benefits of the modal-based SHM of bridges have been recently recognized by some codes and guidelines [14,18]. Examples of assessment of the structural health conditions of bridges by continuous modal-based SHM are reported, for instance, in $[19,20]$, pointing out the potential of the technology but also some issues related to the influence of environmental and operational variables on the estimated modal properties that jeopardize the reliability of damage detection.

The present paper summarizes basic and relevant aspects of OMA and modal-based SHM, and explanatory applications are illustrated with reference to selected case studies involving bridges. The paper is organized as follows. After a brief introduction about OMA, Section 2 presents the application of OMA to some reinforced concrete arch bridges and possible correlations for the prediction of the fundamental frequency; moreover, it shows how the results of modal tests can be used for the validation of a numerical model of a bridge which underwent a provisional intervention after collapse of a pier due to scour; finally, the role of OMA in a vibration serviceability assessment of a footbridge is discussed with reference to a real case study. Section 3 recalls relevant concepts of modal-based SHM and presents some applications of the continuous monitoring of modal parameters; the selected case studies remark the effectiveness of the technology and point out the influence of non-stationarities and environmental and operational variables on the monitoring results. Finally, a summary and final remarks are reported in Section 4. 


\section{Operational Modal Analysis and Applications to Bridges}

\subsection{Basics}

OMA procedures yield experimental estimates of the modal parameters from measurements of the structural response only. While many OMA methods have been derived from input-output modal analysis procedures, over the years OMA has evolved as an autonomous discipline. Its application in the field of civil engineering is very attractive because tests are cheap and fast, and they do not interfere with the ordinary use of the structure. However, very sensitive, low-noise measurement equipment is required to resolve the low amplitude structural vibrations in operational conditions [1]. The fundamental assumptions of OMA are linearity, stationarity, and observability (of the modes of interest). As the input is immeasurable, a broadband excitation is assumed to excite the structure so that all the structural modes in the frequency range of interest are detectable. A random in time and space input has been proved to yield the best modal identification results [21].

OMA methods can be classified according to different criteria. When the domain of implementation is considered, they are defined as time domain methods if they are based on the analysis of response time histories (or, alternatively, correlation functions) and frequency domain methods if spectral density (PSD) functions are processed. Moreover, other relevant distinctions are between parametric (if modal parameter estimates are obtained from a model fitting the data) and non-parametric methods, and between high-order and low-order methods (if the number of identifiable modes is limited by the number of measurement channels).

Popular OMA techniques are the Frequency Domain Decomposition (FDD) [22] and the Stochastic Subspace Identification (SSI) [23]. FDD is a frequency domain, non-parametric OMA method relying on the singular value decomposition of the output PSD matrix. Structural resonances are identified through peak picking in the resulting singular value plots, and the corresponding singular vectors are good estimates of the corresponding mode shapes. The enhanced version of the method (EFDD) is also able to provide damping estimates [24]. SSI is a time domain, parametric OMA method based on a state-space description of the dynamic problem. Realizations of the state matrix and output matrix are obtained from measurements of the structural response through algebraic manipulations and used to extract the modal parameters. Other methods such as the poly-reference least squares complex frequency [25] and Second Order Blind Identification (SOBI) [26] methods are becoming more and more popular because they simplify the identification of the structural modes thus providing interesting opportunities for the automation of OMA. The interested reader can refer to the literature [1] for more details about the theoretical background of OMA methods and their application to civil engineering structures.

\subsection{Output-Only Modal Identification of Arch Bridges}

Reinforced concrete $(\mathrm{RC})$ arch bridges are complex structures whose dynamic characteristics are sometimes difficult to predict, particularly in the presence of frequency-veering and mode hybridization phenomena [27]. Many of the existing RC arch bridges in Italy have been built in the early decades after the World War II according to outdated design codes. Moreover, the traffic loading has increased with respect to the past, and many bridges demand structural interventions to safely sustain the current traffic volumes. However, the studies on RC arch bridges are relatively limited in number, while an extensive technical literature deals with the dynamic response of masonry arch bridges.

This section reports the results of an experimental campaign carried out on highway RC arch bridges in the Campania region, Southern Italy. Based on these tests, a database of modal properties has been collected and complemented with other results found in the technical and scientific literature. Attention is paid to RC arch bridges in Italy with the aim of improving the knowledge of the main parameters and features affecting the dynamic response of a common structural type in Italian roads and highways. 
In 2018 five highway RC arch bridges have been analyzed through OMA tests. Though the names and locations of the bridges must remain confidential, their relevant geometric features and fundamental modal properties are summarized in Table 1. Their typical structural configuration is outlined in Figure 1, which shows similar Italian RC arch bridges erected in the same period (source: maps.google.it). The detailed discussion of the experimental results is out of the scope of the present section; however, some aspects related to the lessons learned executing the tests and processing the vibration measurement data are illustrated.

Table 1. Fundamental modal properties of a set of highway RC bridges in Southern Italy $\left(\phi_{\mathrm{i}}\right.$ means the $\mathrm{i}$-th mode shape, $\mathrm{V}$ is for vertical bending, $\mathrm{H}$ is for horizontal bending).

\begin{tabular}{cccccccc}
\hline $\begin{array}{c}\text { Bridge } \\
\text { Number }\end{array}$ & $\begin{array}{c}\text { Total } \\
\text { Length }(\mathbf{m})\end{array}$ & $\begin{array}{c}\text { Span } \\
\text { Length }(\mathbf{m})\end{array}$ & $\begin{array}{c}\text { Rise Until the } \\
\text { Crown }(\mathbf{m})\end{array}$ & $\mathbf{f}_{\mathbf{1}}(\mathbf{H z})$ & $\mathbf{\phi}_{\mathbf{1}}$ & $\mathbf{f}_{\mathbf{2}}(\mathbf{H z})$ & $\mathbf{\phi}_{\mathbf{2}}$ \\
\hline I & 76.4 & 60.8 & 15.4 & 2.78 & $\mathrm{~V}$ & 3.62 & $\mathrm{H}$ \\
II & 76 & 76 & 19.3 & 2.95 & $\mathrm{H}$ & 3.04 & V \\
III & 60.8 & 60.8 & 18 & 2.85 & $\mathrm{~V}$ & 3.82 & $\mathrm{H}$ \\
IV & 140 & 120 & 32.5 & 1.32 & $\mathrm{H}$ & 1.45 & V \\
V & 60 & 60 & 20.8 & 2.53 & $\mathrm{~V}$ & 3.38 & $\mathrm{H}$ \\
\hline
\end{tabular}
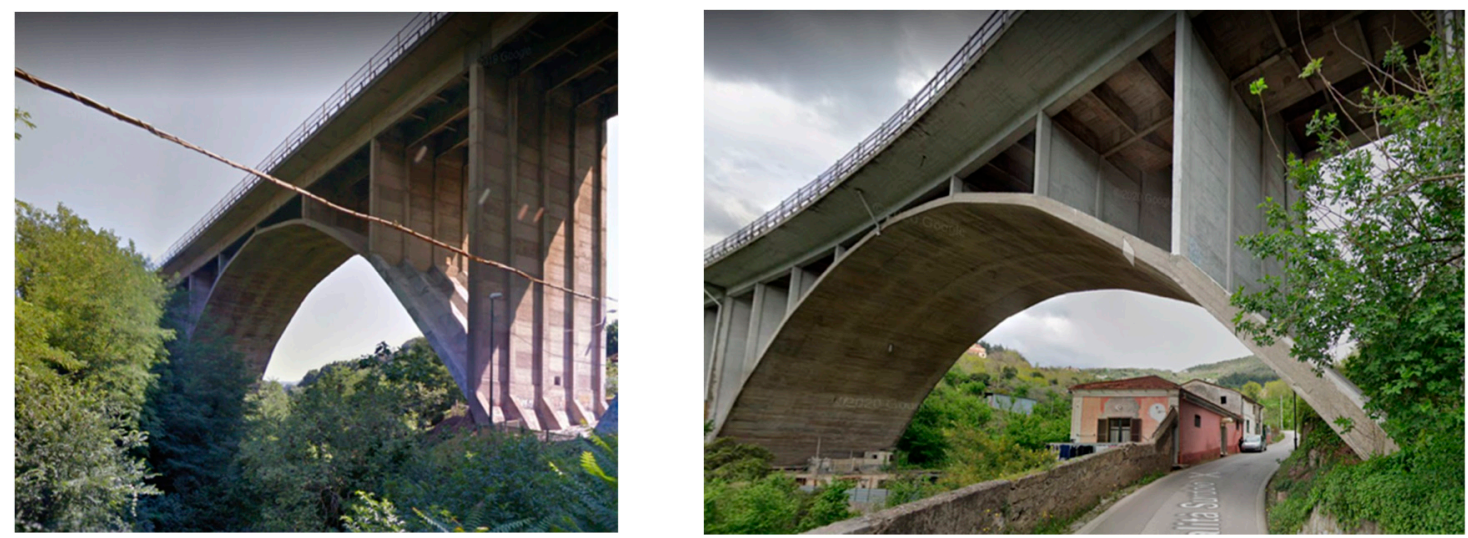

Figure 1. Sample images representative of the tested RC arch bridges (source: maps.google.it).

In particular, the development of correlations for the prediction of the fundamental frequency of $\mathrm{RC}$ arch bridges from basic geometric data is presented. Predictive correlations are certainly useful for the operators who must design and carry out OMA tests, and for the personnel having in charge the management of the bridge and its periodic inspections in the absence of more sophisticated analyses. In order to accomplish this task, additional data concerning homogenous structural configurations have been collected from the literature [28]. For the sake of simplicity, the selected geometrical parameter is the span length, whose correlation with the fundamental frequency of the RC arch bridge in logarithmic form has been investigated, in agreement with similar studies reported in the literature and referring to masonry arch bridges [29]. This is, in more detail, the way the predictive correlations have been set:

- Equation (1) relates the fundamental frequency and the span length $s$ in m without any consideration of the associated mode shape (Figure 2a);

- Equation (2), based on a subset of the available data, applies to the bridges showing vertical antisymmetric mode shapes associated to the fundamental frequency (Figure 2b).

$$
\begin{aligned}
& f=-4.527 \cdot \ln (s)+22.041 \\
& f=-4.188 \cdot \ln (s)+20.729
\end{aligned}
$$




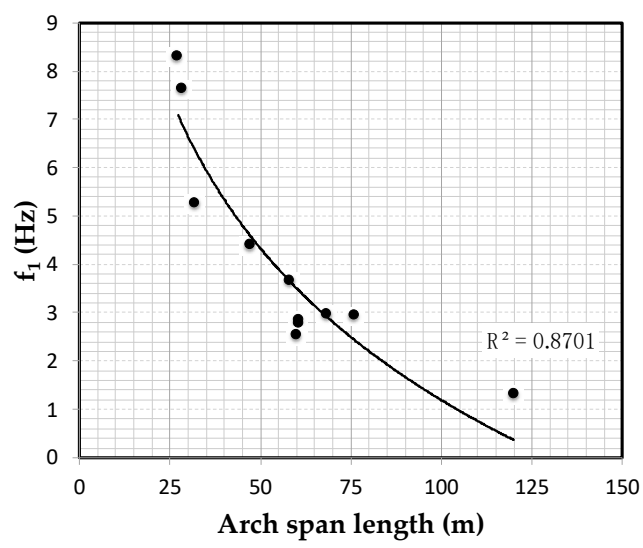

(a)

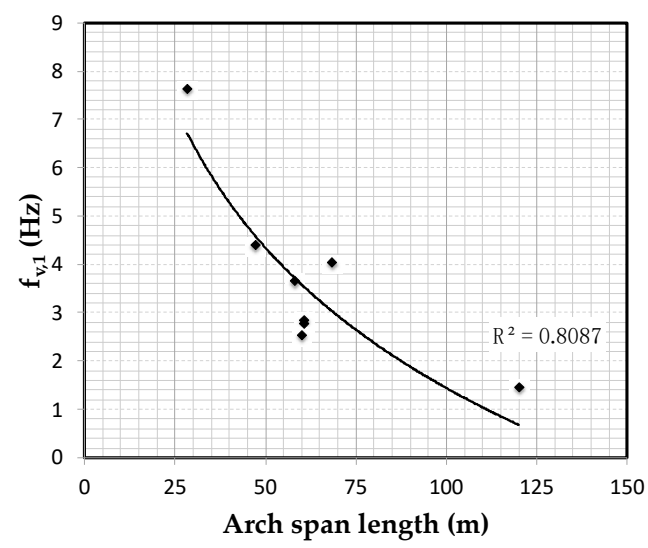

(b)

Figure 2. Empirical correlations for the prediction of the fundamental frequency of RC arch bridges (a), the fundamental frequency of $\mathrm{RC}$ arch bridges corresponding to an antisymmetric vertical bending mode (b).

The prediction accuracy of the empirical correlations has been checked against the modal identification results reported in [30,31] for similar RC arch bridges located in Central Italy and Portugal.

It is worth noting that, even if conclusive results cannot be drawn yet, and more data need to be collected to reach a firm conclusion, the results obtained from the use of the empirical correlations to the considered validation examples are encouraging (Table 2) and well correlated to the modal frequencies of bridges characterized by a maximum span length lower than $100 \mathrm{~m}$.

Table 2. Predictive performance of the empirical correlations for the estimation of the fundamental frequencies of RC arch bridges.

\begin{tabular}{ccccc}
\hline Bridge & Span $(\mathbf{m})$ & $\mathbf{f}_{\mathbf{e x p}} \mathbf{( H z )}$ & $\mathbf{f}_{\text {corr }} \mathbf{( H z )}$-Equation (1) & $\mathbf{f}_{\text {corr }} \mathbf{( H z ) \text { -Equation (2) }}$ \\
\hline Montecastelli bridge [30] & 68.7 & 3.18 & 2.89 & 3.01 \\
Arch bridge in Portugal [31] & 80 & 2.11 & 2.20 & 2.38 \\
\hline
\end{tabular}

\subsection{Model Validation}

This section illustrates a sample application of OMA aimed at validating the Finite Element (FE) model of a road bridge in Southern Italy, the Ufita bridge. The bridge has been tested in the context of a wider research project (PON - National Operational Program 2007-2013 Research Project "STRIT"-OR3 Use of advanced monitoring techniques, coordinated by Prof. G. Fabbrocino) investigating different tools and technologies for the risk management of transportation infrastructures. A steel-concrete composite structure characterized the bridge, with longitudinal steel beams connected by transverse and diagonal steel profiles forming a truss structure, and an $8.8 \mathrm{~m}$-wide and $0.3 \mathrm{~m}$-high RC deck—see Figure 3a,b.

The structure can be schematically represented as a continuous beam with four supports; in the original configuration, the three spans were about $27 \mathrm{~m}$ long, with a total length of the bridge of about $81 \mathrm{~m}$. The two intermediate piers, located in the riverbed, were $6 \mathrm{~m}$ high, with a $2.4 \times 9 \mathrm{~m} \mathrm{RC}$ cross section. In 2013 one of the two piers collapsed during a major flood event, and it was replaced by a provisional pier located in a position $8.45 \mathrm{~m}$ away from the original one, on a more stable part of the riverbed. An overview of the bridge with the provisional pier is provided in Figure 3a.

The implementation of the FE model (Figure 3c) in SAP2000 [32] has followed an accurate geometric survey by a laser scanner. The deck was modelled by shell elements, while one-dimensional elements were used for the steel beams. Nominal values were adopted for the physical and elastic properties of concrete and steel [33]. 
The output-only modal identification of the bridge was carried out by installing twenty uniaxial IEPE (Integrated Electronics Piezo-Electric) accelerometers with the following characteristics: $10 \mathrm{~V} / \mathrm{g}$ sensitivity, $\pm 0.5 \mathrm{~g}$ full-scale range. The data acquisition system was characterized by a sigma-delta ADC (analog- to-digital converter) with 24-bit resolution, $102 \mathrm{~dB}$ dynamic range, and built-in analog antialiasing filter. The sensor layout is schematically shown in Figure 4. The positions and orientations of the sensors were defined in a way that ensured the observability of bending as well as torsional modes. All sensors were installed on the deck.

The response of the bridge to ambient vibrations was recorded for $1 \mathrm{~h}$ at a sampling rate of $100 \mathrm{~Hz}$. The time series were bandpass filtered and decimated before modal parameter estimation. The decimated sampling rate was $20 \mathrm{~Hz}$.

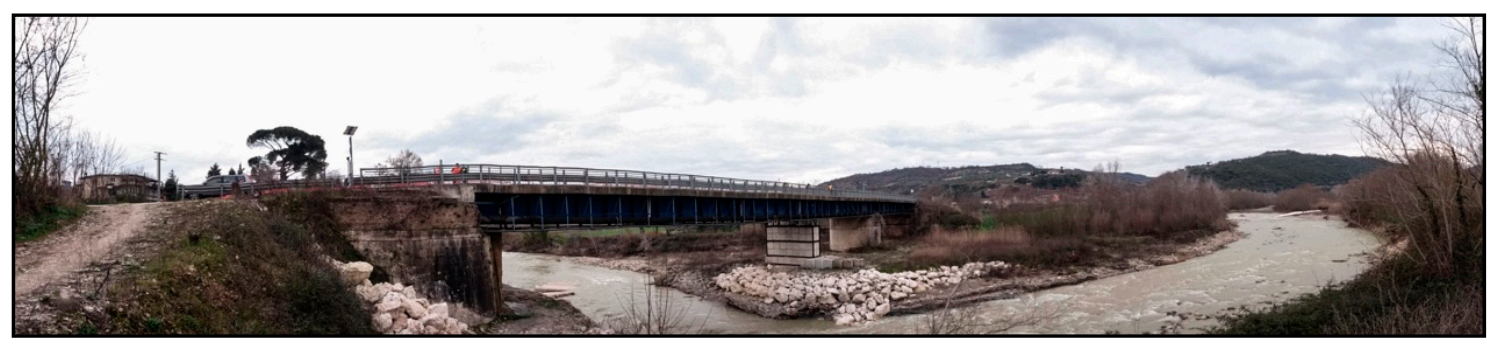

(a)

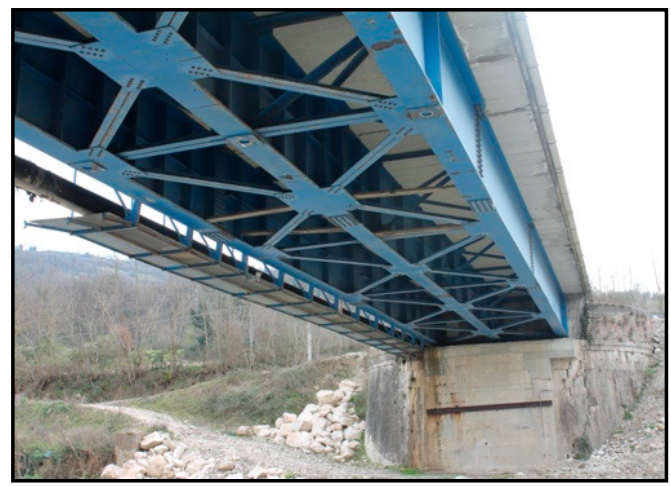

(b)

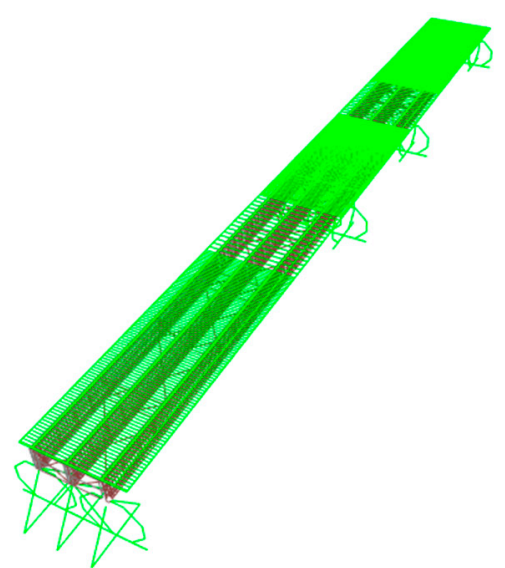

(c)

Figure 3. Ufita bridge overview (a); view of the composite deck (b); FE model (c).

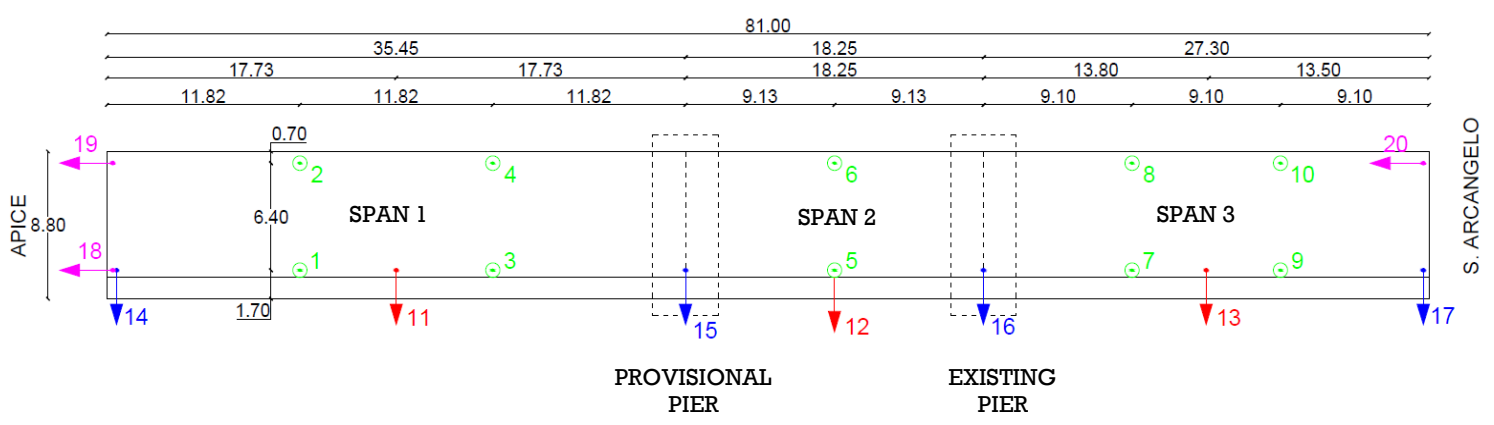

Figure 4. Ufita bridge plain view: sensor layout (length in $\mathrm{m}$ ).

FDD and SSI were applied for modal parameter estimation. When FDD was applied, a Hanning window and $50 \%$ overlap were adopted in the computation of the PSDs. A large number of averages in the computation of PSDs ensured that the random error was kept low; in addition, the adoption of a 
fine frequency resolution of $0.01 \mathrm{~Hz}$ ensured that the bias was also minimum. When SSI was applied, the number of block rows and the maximum model order were selected after a sensitivity analysis aimed at enhancing the quality of the resulting stabilization diagram [34].

The modal identification results are summarized in Table 3, where the identified frequencies, $\mathrm{f}$, and the associated damping ratio, $\xi$, are given. FDD and SSI provided very consistent estimates. All the identified modes were normal.

Table 3. Ufita bridge: output-only modal identification results.

\begin{tabular}{cccc}
\hline Mode & $\mathbf{f ~ ( H z )}$ & $\xi \mathbf{( \% )}$ & Mode Shape Description \\
\hline I & 3.75 & 0.7 & Out-of-plane bending \\
II & 4.39 & 2.4 & In-plane bending \\
III & 5.40 & 1.2 & Torsion \\
IV & 5.90 & 2.0 & Out-of-plane bending \\
\hline
\end{tabular}

A good correlation between the results of the numerical and experimental modal analysis can be observed (Table 4), thus confirming the validity of the FE model which is able to reproduce quite well the fundamental modes of the bridge in operation. The largest discrepancy can be observed in terms of the natural frequency of the second mode; moreover, while the test showed that the fundamental modes were well separated, the FE model yielded close natural frequency estimates for the first two and the second two modes. However, the correlation in terms of mode shapes was satisfactory for all the considered modes. Thus, even if the FE model could not be referred to as fully representative of the response of the bridge in operational conditions, it already provided encouraging results in view of the subsequent structural analyses aimed at assessing the current safety level under static and dynamic loadings.

Table 4. Ufita bridge: comparison between numerical and experimental results.

\begin{tabular}{ccccc}
\hline Mode & $\mathbf{f}_{\text {exp }} \mathbf{( H z )}$ & $\mathbf{f}_{\text {FEM }} \mathbf{( H z )}$ & $\boldsymbol{\Delta} \mathbf{f} \mathbf{( \% )}$ & $\mathbf{M A C}$ \\
\hline I & 3.75 & 3.55 & -5 & 0.97 \\
II & 4.39 & 3.58 & -18 & 0.97 \\
III & 5.40 & 5.97 & 11 & 0.85 \\
IV & 5.90 & 6.03 & 2 & 0.87 \\
\hline
\end{tabular}

\subsection{Vibration Serviceability Assessment of a Footbridge}

Footbridges represent a special class of bridges, since they are usually subjected to lower loads with respect to highway and railroad bridges; as a result, they are often characterized by slender structures which make them prone to human-induced vibrations due to the closeness between the natural frequencies of the footbridge and the pace frequency during walking and/or running $[10,35,36]$. Vibration serviceability is therefore a primary concern for this type of structure, and several guidelines are currently available to assess the vibration response of footbridges and verify the corresponding serviceability limit state (see, for instance, [37-39]).

In particular, the available codes and guidelines typically define some limits to the natural frequencies of footbridges to avoid pedestrian-induced resonance. In case those limits are not fulfilled, the vibration serviceability of the footbridge must be checked by comparing the maximum vertical and horizontal accelerations under human-induced loadings with some reference limits [10].

The present section illustrates the evaluation of the vibration serviceability of a footbridge though experimental testing. In particular, the modal parameters of the structure were identified through an OMA test, first; after having checked that the identified natural frequencies do not satisfy code limits, measurements of the structural response under various pedestrian-induced excitation were carried out; the maximum recorded accelerations were finally compared with code limits to assess the vibration serviceability of the footbridge. 
The structure under test is the pedestrian bridge (Figure 5) located in the recently built hospital complex in the Eastern part of Naples (Southern Italy), the so-called "Ospedale del Mare". It is a steel tied-arch bridge with a $5.0 \mathrm{~m}$-wide steel-concrete composite deck. The span length is $66.0 \mathrm{~m}$. The footbridge is a part of the pedestrian path from the parking area for healthcare personnel to the hospital.

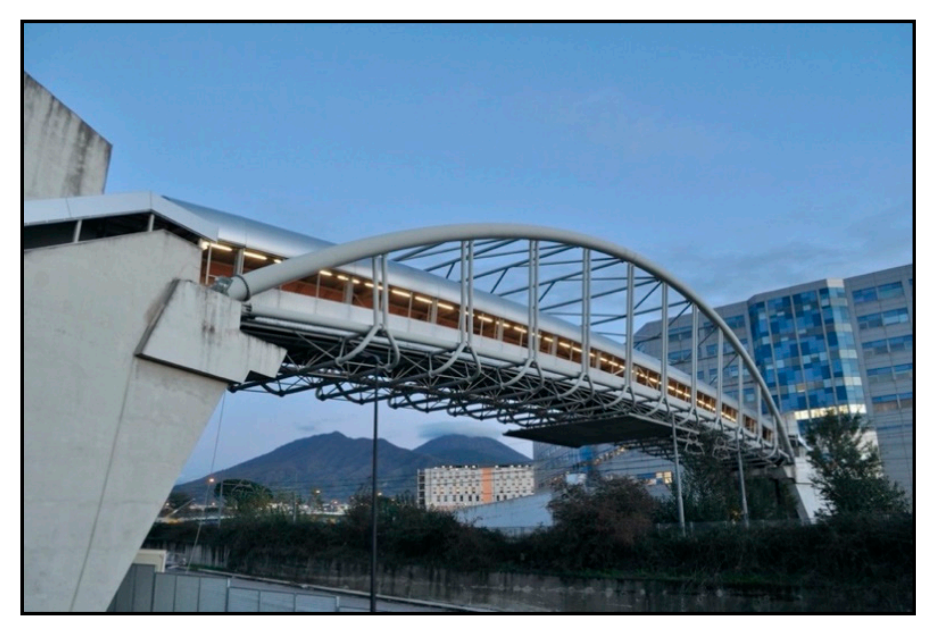

Figure 5. The pedestrian bridge in the "Ospedale del Mare" hospital complex in Naples, Italy.

The sensor layout shown in Figure 6 was adopted for the output-only modal identification of the footbridge. Fifteen force balance accelerometers $( \pm 0.5 \mathrm{~g}$ full-scale range, $20 \mathrm{~V} / \mathrm{g}$ sensitivity) were installed on the deck. The sensor layout ensured the observability of the vertical and horizontal bending modes as well as torsional modes. The measurement equipment was completed by a data acquisition system characterized by 16-bit resolution and built-in analog antialiasing filter.

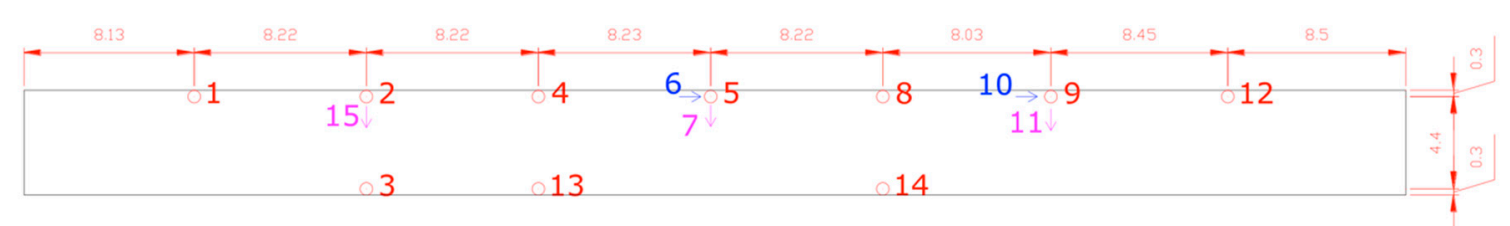

Figure 6. "Ospedale del Mare" footbridge: sketch of the plan view and sensor layout (length in m).

The ambient vibration response of the footbridge was recorded for $1700 \mathrm{~s}$ at a sampling frequency of $100 \mathrm{~Hz}$. After a preliminary visual inspection and data validation [40], the collected data were bandpass filtered and decimated by a factor of 5. FDD and SSI have been applied for modal parameter estimation.

On the analogy with the case study discussed in the previous section, a Hanning window, $50 \%$ overlap and $0.01 \mathrm{~Hz}$ frequency resolution have been considered in the computation of PSDs, while a sensitivity analysis with respect to the number of block rows has been carried to enhance the quality of the stabilization diagram resulting from the application of SSI. The singular value plots obtained by applying FDD to the collected dataset are shown in Figure 7.

The results of modal identification are reported in Table 5. All the identified modes were normal. Very consistent results have been obtained from the two OMA methods, as confirmed also by the CrossMAC values [1] close to 1 denoting a very good correlation among the mode shape estimates provided by FDD and SSI. 


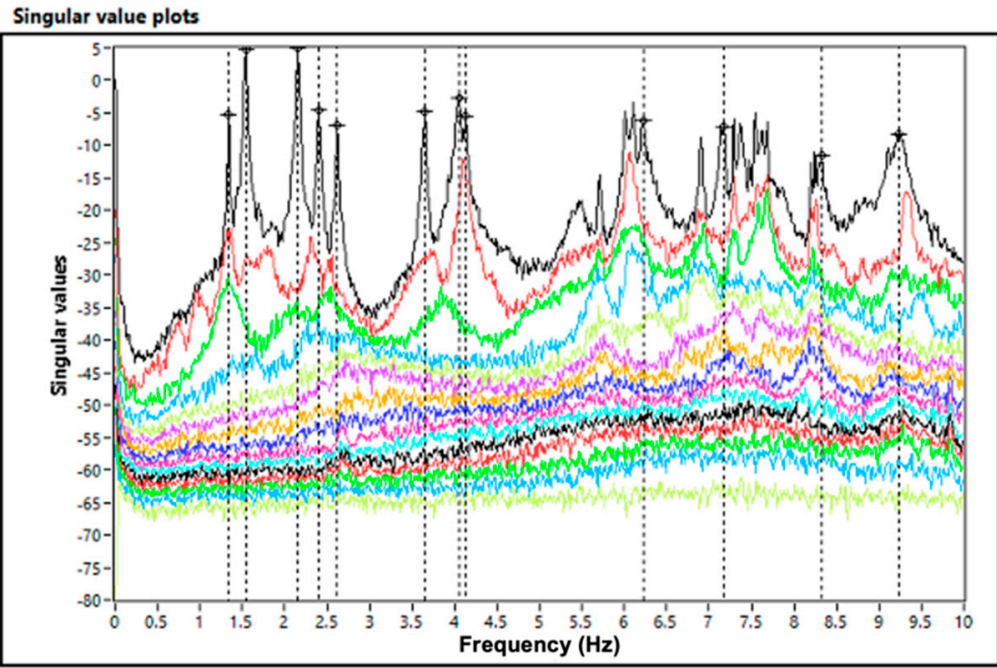

Figure 7. "Ospedale del Mare" footbridge: singular value plots (continuous colored lines) and identified frequencies (dashed lines).

Table 5. "Ospedale del Mare" footbridge: output-only modal identification results.

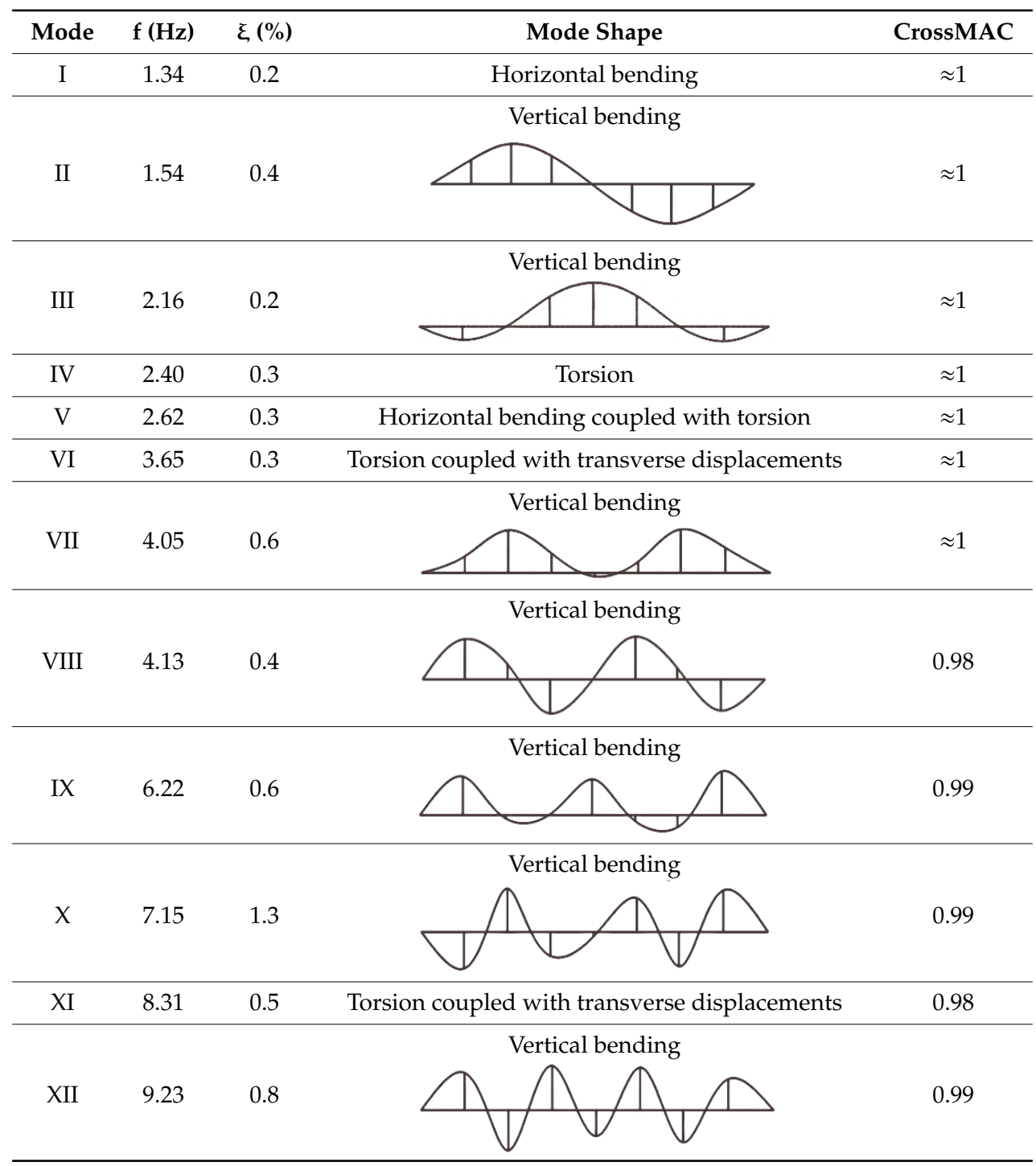


As the acceptance criteria of the modal response of the structure are concerned, it is worth noting that only simplified thresholds and/or critical frequency bandwidth are reported in relevant National and International design codes. Consequently, whenever pedestrian bridges are concerned, different sources are needed. In the following, reference is made to two relevant documents: the first is the report of the project "Human induced vibrations of steel structures", herein referred to as HIVOSS [37]; the second was released by the French Technical Department for Transport, Roads and Bridges Engineering and Road Safety (Service d'études techniques des routes et autoroutes-Sétra), herein referred to as SETRA [39]. In particular, the critical frequency range for vertical modes is $1 \div 5 \mathrm{~Hz}$ according to SETRA, and $1.24 \div 4.6 \mathrm{~Hz}$ according to HIVOSS; the critical frequency ranges for transverse modes are $0.3 \div 2.5 \mathrm{~Hz}$ and $0.5 \div 1.2 \mathrm{~Hz}$ for SETRA and HIVOSS, respectively.

Comparing the modal identification results in Table $5-\mathrm{f}$ identifies the modal frequency, $\xi$ is the corresponding damping ratio-with the critical frequency ranges for vertical and transverse modes points out that the vertical and transverse accelerations under pedestrian-induced excitation also require a more detailed analysis. To this aim the acceleration response of the footbridge to pedestrians walking and running on it has been recorded and analyzed. In particular, the following tests have been carried out:

- 1 pedestrian walking along the middle of the deck-1p wm-(Figure 8a);

- 1 pedestrian walking along one side of the deck-1p ws;

- 2 pedestrians walking along the middle of the deck-2p wm-(Figure $8 b$ );

- 2 pedestrians walking along one side of the deck-2p ws;

- 5 pedestrians walking along the middle of the deck-5p wm;

- 5 pedestrians walking along one side of the deck-5p ws;

- 10 pedestrians walking along the middle of the deck, one way-10p wo-(Figure 8c);

- 10 pedestrians walking along one side of the deck, return-10p wr;

- 1 pedestrian running along the middle of the deck-1p rm;

- 1 pedestrian running along one side of the deck-1p rs-(Figure $8 d$ );

- 2 pedestrians with a loaded trolley walking along the middle of the deck to simulate the passage of stretcher bearers-2t wm-(Figure 8e);

- 2 pedestrians with a loaded trolley walking along one side of the deck to simulate the passage of stretcher bearers-2t ws;

- 2 pedestrians with a loaded trolley running along the middle of the deck to simulate the passage of stretcher bearers-2t rm;

- 2 pedestrians with a loaded trolley running along one side of the deck to simulate the passage of stretcher bearers-2t rs.

Two passages for each test case have been recorded and processed to extract the maximum vertical and horizontal accelerations exhibited by the structure. The results are reported in Table $6 \mathrm{a}$ for the first passage and Table $6 \mathrm{~b}$ for the second one. 
Table 6. (a) "Ospedale del Mare" footbridge: maximum recorded acceleration $\left(a_{\max }\right)$ in horizontal $\left(a_{h}\right)$ and vertical $\left(\mathrm{a}_{\mathrm{v}}\right)$ direction under different pedestrian-induced loadings, first passage. (b) "Ospedale del Mare" footbridge: maximum recorded acceleration $\left(a_{\max }\right)$ in horizontal $\left(a_{h}\right)$ and vertical $\left(a_{v}\right)$ direction under different pedestrian-induced loadings, second passage.

\begin{tabular}{|c|c|c|c|c|c|c|c|c|c|c|c|c|c|c|}
\hline \multicolumn{15}{|c|}{ (a) } \\
\hline $\begin{array}{l}a_{\max } \\
\left(\frac{\mathrm{cm}}{\mathrm{s}^{2}}\right)\end{array}$ & $\begin{array}{c}1 p \\
w m\end{array}$ & $\begin{array}{l}1 p \\
\text { ws }\end{array}$ & $\begin{array}{c}2 p \\
\text { wm }\end{array}$ & $\begin{array}{l}2 p \\
w s\end{array}$ & $\begin{array}{c}5 p \\
\text { wm }\end{array}$ & $\begin{array}{l}5 p \\
\text { ws }\end{array}$ & $\begin{array}{l}10 p \\
\text { wo }\end{array}$ & $\begin{array}{l}10 p \\
w r\end{array}$ & $\begin{array}{l}\text { 1p } \\
\text { rm }\end{array}$ & $\begin{array}{l}1 p \\
\text { rs }\end{array}$ & $\begin{array}{c}2 t \\
\text { wm }\end{array}$ & $\begin{array}{c}2 t \\
\text { ws }\end{array}$ & $\begin{array}{c}2 \mathrm{t} \\
\mathrm{rm}\end{array}$ & $2 \mathrm{t} \mathrm{rs}$ \\
\hline$a_{h}$ & 0.8 & 1.1 & 1.0 & 1.1 & 1.6 & 2.0 & 2.0 & 1.5 & 1.1 & 2.8 & 1.3 & 2.0 & 1.8 & 2.3 \\
\hline$a_{v}$ & 4.3 & 3.6 & 6.1 & 4.8 & 6.2 & 8.8 & 8.8 & 11.4 & 15.8 & 16.1 & 12.1 & 13.5 & 24.8 & 21.2 \\
\hline \multicolumn{15}{|c|}{ (b) } \\
\hline $\begin{array}{l}a_{\max } \\
\left(\frac{\mathrm{cm}}{\mathrm{s}^{2}}\right)\end{array}$ & $\begin{array}{c}1 p \\
w m\end{array}$ & $\begin{array}{l}1 p \\
\text { ws }\end{array}$ & $\begin{array}{c}2 p \\
w m\end{array}$ & $\begin{array}{l}2 p \\
w s\end{array}$ & $\begin{array}{c}5 p \\
w m\end{array}$ & $\begin{array}{l}5 p \\
\text { ws }\end{array}$ & $\begin{array}{l}10 p \\
\text { wo }\end{array}$ & $\begin{array}{c}10 p \\
w r\end{array}$ & $\begin{array}{l}1 \mathrm{p} \\
\mathrm{rm}\end{array}$ & $\begin{array}{l}1 p \\
\text { rs }\end{array}$ & $\begin{array}{c}2 t \\
w m\end{array}$ & $\begin{array}{c}2 t \\
\text { ws }\end{array}$ & $\begin{array}{c}2 t \\
\mathrm{rm}\end{array}$ & $2 \mathrm{t} \mathrm{rs}$ \\
\hline$a_{h}$ & 0.9 & 1.1 & 0.8 & 1.1 & 1.6 & 2.2 & 2.1 & 2.5 & 1.2 & 1.6 & 1.6 & 1.8 & 1.8 & 2.0 \\
\hline$a_{\mathrm{V}}$ & 3.4 & 3.4 & 4.7 & 4.6 & 5.9 & 7.1 & 7.6 & 8.6 & 16.6 & 17.7 & 12.3 & 13.6 & 21.6 & 22.8 \\
\hline
\end{tabular}

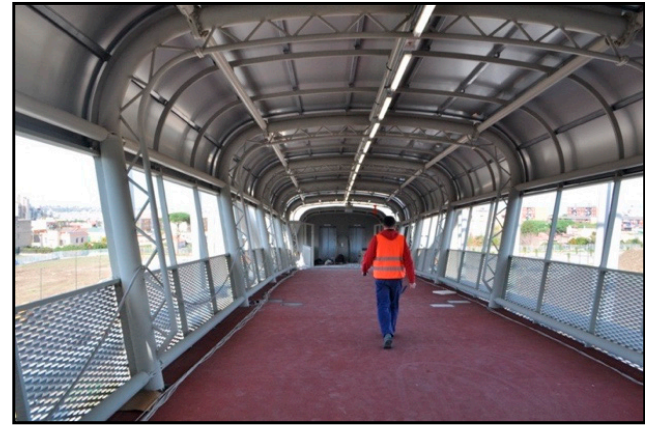

(a)

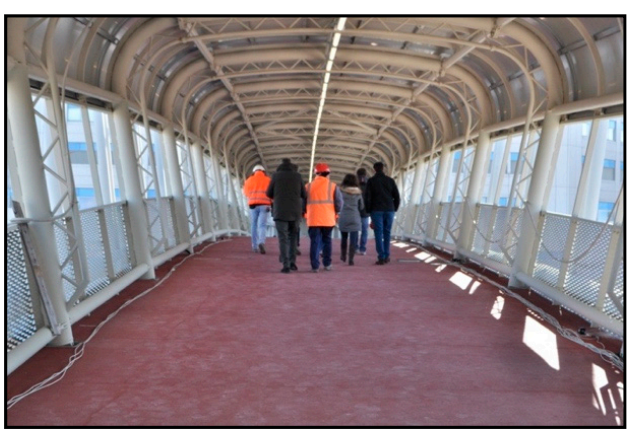

(c)

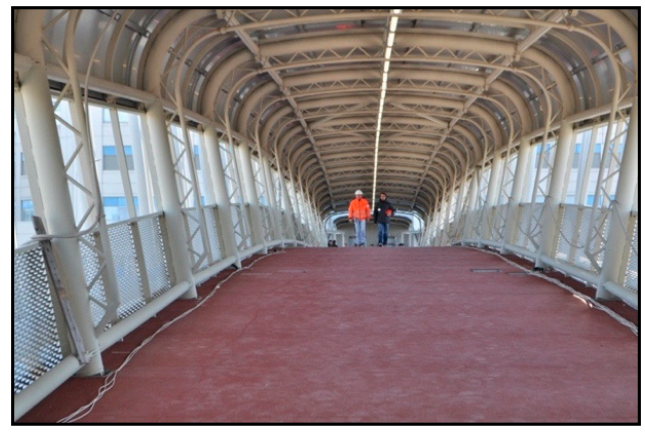

(b)

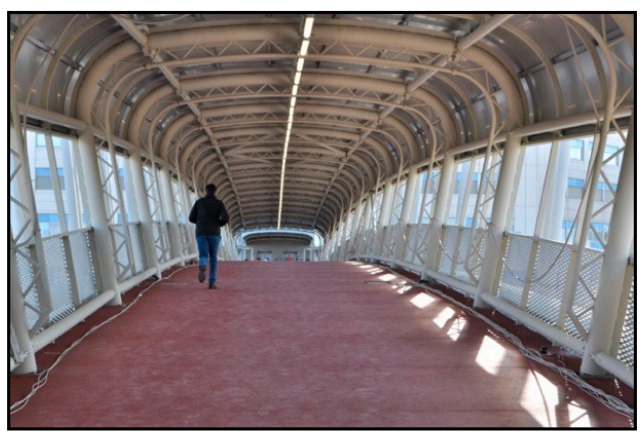

(d)

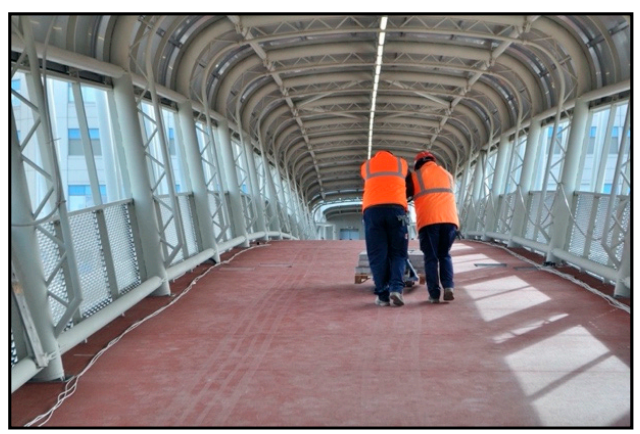

(e)

Figure 8. "Ospedale del Mare" footbridge: vibration measurements under pedestrian-induced loadings: 1 walking pedestrian (a), 2 walking pedestrians (b), 10 walking pedestrians (c), 1 running pedestrian (d), 2 walking pedestrians with loaded trolley (e). 
In addition to the previously mentioned test cases, the vibration response of the footbridge has been measured also in the case of ten pedestrians randomly walking on the deck, obtaining $2.15 \mathrm{~cm} / \mathrm{s}^{2}$ and $11.47 \mathrm{~cm} / \mathrm{s}^{2}$ as maximum values of the horizontal and vertical acceleration, respectively.

The measured peak accelerations have been compared with the limits defined by the guidelines [37,39] and reported in Table 7 for the sake of completeness. Even though the natural frequencies were allotted in the critical ranges, the structure exhibited peak vertical and horizontal accelerations complying with the limits associated to the maximum comfort level (CL 1).

The described tests for vibration serviceability assessment were part of the tests carried out at the commissioning stage; the footbridge is now fully operational.

Table 7. Vertical $\left(\mathrm{a}_{\mathrm{v}, \text { limit }}\right)$ and transverse $\left(\mathrm{a}_{\mathrm{h}, \text { limit }}\right)$ acceleration limits for different comfort levels.

\begin{tabular}{cccccc}
\hline \multirow{2}{*}{ Comfort Level } & \multirow{2}{*}{ Description } & \multicolumn{2}{c}{$\mathbf{a}_{\mathbf{v}, \text { limit }}\left(\mathbf{c m} / \mathbf{s}^{\mathbf{2}}\right)$} & \multicolumn{2}{c}{$\mathbf{a}_{\mathbf{h}, \text { limit }}\left(\mathbf{c m} / \mathbf{s}^{\mathbf{2}}\right)$} \\
\cline { 3 - 5 } & & HIVOSS [37] & SETRA [39] & HIVOSS [37] & SETRA [39] \\
\hline CL 1 & Maximum & $<50$ & $<50$ & $<10$ & $<15$ \\
CL 2 & Medium & $50 \div 100$ & $50 \div 100$ & $10 \div 30$ & $15 \div 30$ \\
CL 3 & Minimum & $100 \div 250$ & $100 \div 250$ & $30 \div 80$ & $30 \div 80$ \\
CL 4 & Unacceptable & $>250$ & $>250$ & $>80$ & $>80$ \\
\hline
\end{tabular}

\section{Modal-Based Structural Health Monitoring and Applications to Bridges}

\subsection{Basics}

Newly built structures are relatively few nowadays in many European Countries, while most of the infrastructure stock has been designed and erected decades ago. Thus, structural deterioration and degradation are primary concerns due to the related increase in maintenance costs and of the frequency of structural failures. As mentioned in the previous sections, excessive loads may reduce the residual life of the bridge and endanger its safety. Therefore, there is an urgent need for rational and effective approaches for the structural maintenance of substandard structures. In this context, modal-based SHM is increasing its attractiveness because of the possibility to carry out timely damage detection on a remote and automated basis.

Several damage detection techniques employing modal parameters or derived quantities as damage sensitive features are documented in the technical literature. They assume that damage affects the mass and/or stiffness properties of the structure (including external and/or internal restraints) [41]. Modal-based damage detection is global in nature, and this is certainly an advantage over traditional non-destructive testing methods since the location of damage must not be known a priori, and accessibility is not a primary requirement.

Frequency shifts are frequently used as damage indicators because natural frequencies can be estimated with good accuracy and in a relatively simple way $[19,42,43]$. However, while their global nature can be successfully exploited for damage detection, this feature might yield some limitations for damage localization. The use of modal damping ratios as damage indicators is less frequent because of the larger uncertainties affecting the estimates with respect to natural frequencies and mode shapes. Nevertheless, studies aimed at detecting damage from damping variations can be found in the literature [44].

The use of mode shapes as damage indicators has advantages related to the lower sensitivity to environmental effects with respect to natural frequencies, and to the availability of spatial information that can be used to localize the damage. The changes in the mode shapes can be evaluated at a global level by means of the Modal Assurance Criterion (MAC) [45], and local perturbations can be estimated via the Coordinate Modal Assurance Criterion (COMAC) [46] and other similar indexes. However, the applications of the MAC and COMAC to damage detection in bridges demonstrated a limited reliability being prone to false damage detection, so that attention has been focused on different indexes such as the mode shape curvature [47], the modal strain energy [48], the modal flexibility [49] and the 
modal interpolation error [50]. It is clear that the above-mentioned indexes are not completely free of drawbacks and limitations, which mainly rely on the number of identified modes, the level of noise in the measurements and the need for mass-scaled mode shapes in the case of the modal flexibility. A comparative performance assessment of these damage indicators with reference to an RC bridge can be found in [51]. In spite of the previously mentioned limitations, modal-based SHM currently represents a widely accepted technology also thanks to the recent development of reliable and robust automated OMA procedures, which make possible the continuous monitoring of modal parameters while keeping the accuracy of their estimates high.

Following the advances in the area of automated OMA procedures, permanent monitoring systems could be developed, as an alternative to periodic monitoring strategies. Permanent monitoring systems work on a continuous basis measuring relevant physical (such as temperature, humidity, and so on) as well as mechanical parameters (strains, velocities, accelerations) and extract by appropriate signal processing techniques the related damage sensitive features (modal parameters, etc.) to assess the health state of the target structure. The conceptual advantage of permanent monitoring is the possibility of applying advanced data mining and data fusion procedures to detect unexpected and/or anomalous conditions directly from the incoming measurements of the structural response. However, the large volumes of data to be processed and eventually transmitted make permanent monitoring more expensive and difficult to design and manage than periodic monitoring. This consists of the installation of a sensor network on the target structure for a limited time, from a few hours to some weeks depending on the objectives of the assessment. Periodic monitoring is often used in conjunction with FE model updating for model-based damage detection, as opposed to data-driven damage detection. While periodic, model-based monitoring can represent an effective diagnostic tool, its most relevant drawback is associated to its discontinuous nature, which prevents the observation of slowly varying phenomena, such as those due to environmental effects, or sudden events, such as earthquakes.

From this perspective, permanent data-driven monitoring seems to better fit the objective of timely damage detection than periodic monitoring. On the other hand, the applications of permanent modal-based SHM to bridges must tackle some specific challenges related to the accuracy of the modal parameter estimates in the presence of non-stationarities of the structural response, and of environmental and operational factors. The latter might yield changes of the modal parameters of the same order of magnitude of the damage-induced variations, thus causing problems of false and/or missed alarms [41]. In the following, the potential of modal-based SHM as a global method for remote damage detection is discussed with reference to a laboratory application [52]. The reliability of modal parameter monitoring in the presence of non-stationary responses due to vehicle-induced excitations is also reviewed. Finally, the compensation of the influence of environmental and operational variables is illustrated with reference to a specific application to a real bridge.

\subsection{Modal-Based Damage Detection}

The present section briefly reports the main findings of a laboratory test on shaking tables aimed, among the rest, at assessing the applicative perspectives of modal-based damage detection as a global SHM strategy for existing bridges in earthquake-prone regions. It is one of the laboratory activities carried out in the context of the PON 2007-2013 Research Project "STRIT" aimed at detecting earthquake-induced damage at unmeasured locations through the monitoring of the fundamental natural frequencies. More details about the test specimen, designed according to obsolete codes, and data processing procedures can be found in [52]. Brittle failures due to shear and insufficient ductility due to inadequate anchorage detailing or lap splicing, associated to the use of smooth-steel reinforcement bars and low-strength concrete, mark the seismic response of substandard circular piers. Modal-based damage detection techniques for the SHM of existing bridges in earthquake-prone areas were validated by means of shaking table tests carried on a 1:3 scale single span bridge representative of existing highway bridges built in the 1960s in Italy (Figure 9). 


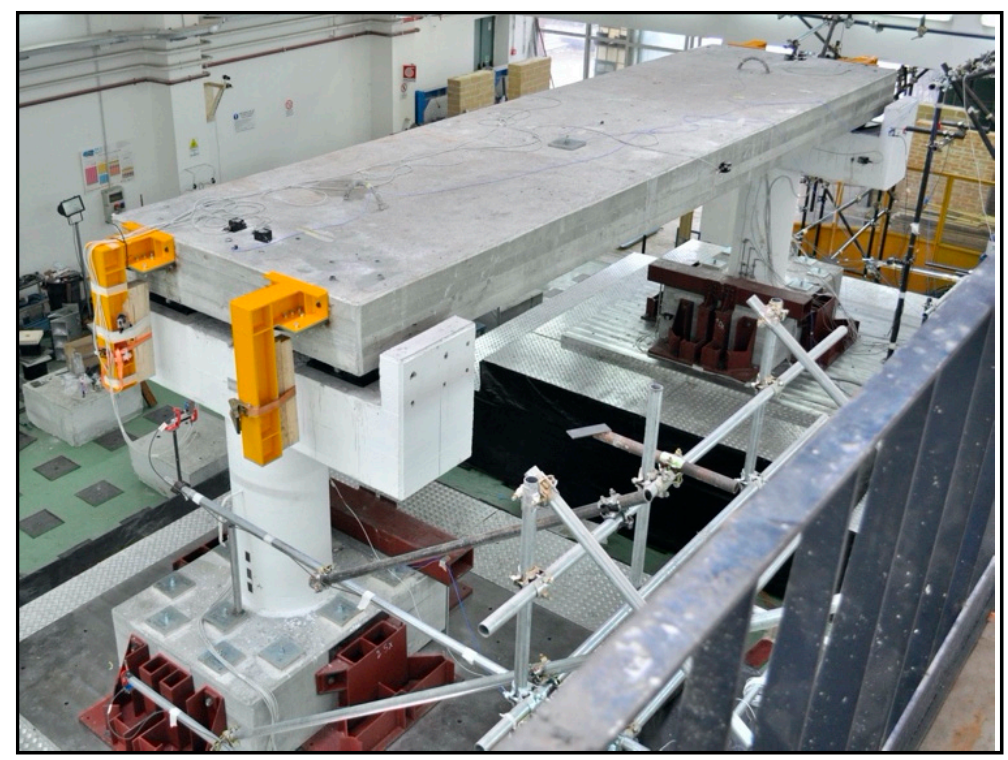

Figure 9. The scaled bridge specimen installed on the shaking table system.

To this end, the specimen was equipped with a monitoring system able to continuously process the ambient vibration response of the structure in order to provide estimates of its fundamental modal parameters. During the tests, the response of the structure under different support conditions (simply supported, and with seismic isolation devices) was analyzed. Following the concept of a remote and automated seismic damage detection system, the ambient vibration response of the structure was continuously recorded before as well as after the application of earthquake shakings. The health assessment of the structure was carried out afterwards by analysing the shifts in the natural frequencies and the changes in the mode shapes due to the shaking.

Twelve force-balance accelerometers were installed on the deck so that observability of the fundamental bending and torsional modes was ensured. For each structural configuration (as-built, retrofitted), the ambient vibration response of the bridge was recorded for about two hours in the healthy state as well as after shaking. Modal parameters were progressively estimated from 600 s-long time histories of the structural response.

Figure 10 clearly shows the different behavior of the as-built bridge (Figure 10a) with respect to the retrofitted bridge with seismic isolation devices (Figure 10b). In the latter configuration, in fact, the natural frequencies remained unaltered after shaking, confirming that no damage occurred. Similar results were obtained by comparing the mode shapes before and after shaking [52]. In the as-built configuration, on the contrary, the bridge exhibited clear drops in the natural frequency time series, confirming the occurrence of damage as a result of the applied shaking. This caused crack opening at the base of one of the piers (Figure 11). This was recognized as a critical cross section because of the construction joint at the interface between the pier and foundation and the lap splice of longitudinal smooth reinforcements. No other cracks occurred in the structure, but the observed damage yielded a significant change of the dynamic properties (natural frequencies as well as mode shapes) in spite of the partial closure of the crack at the end of the shaking test that limited the possibility to visually appreciate the severity of the damage. Thus, the present case study points out the potentialities of modal-based SHM systems for remote damage detection in earthquake-prone regions, even when damage is partially hidden at the end of ground shaking and it is located far from the installed sensors. The interested reader can refer to [52] for more details about the statistical characterization of the healthy and damaged state of the bridge model from the observed time series of the modal properties. 


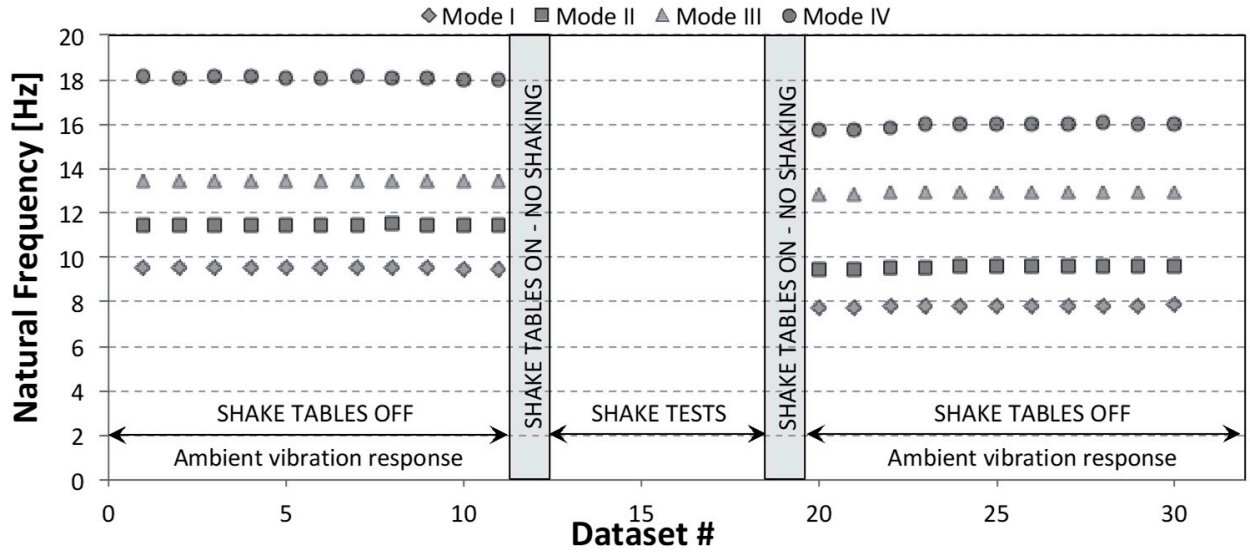

(a)

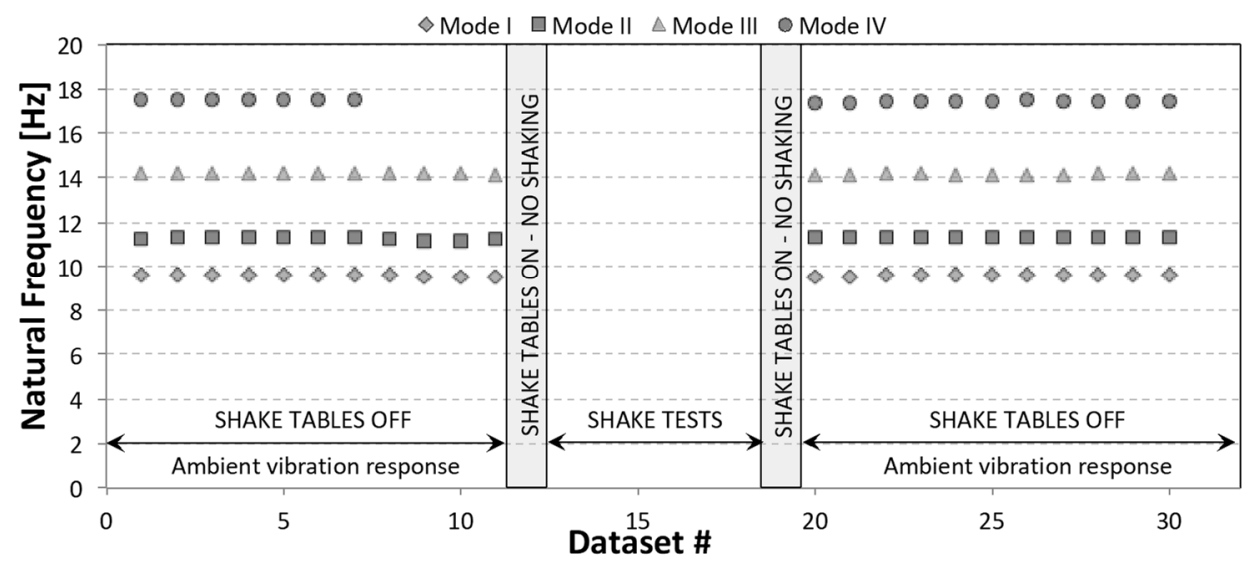

(b)

Figure 10. The bridge model: natural frequency time series in the as-built (a) and retrofitted (b) configuration before and after shaking (adapted from [52]).

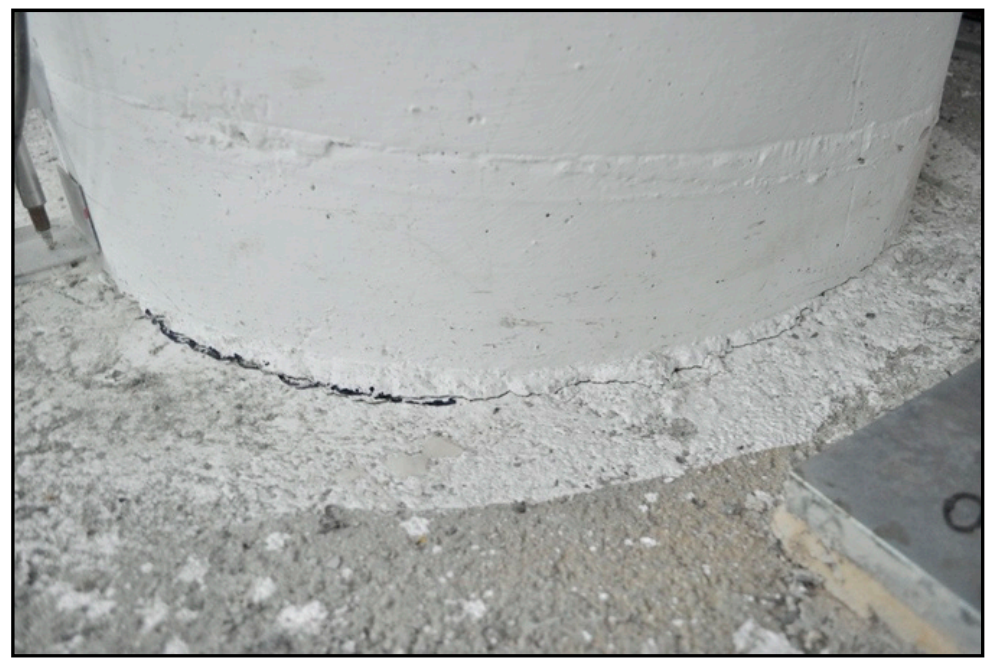

Figure 11. The bridge model: observed crack after shaking.

\subsection{Traffic-Induced Transient Response}

The assumption of linear stationary structural vibration responses behind several OMA methods is frequently not fulfilled in real-world applications. Large non-stationary (and often non-linear) 
responses may be due to extreme natural events, such as earthquakes; however, vehicle-induced excitations can also yield a non-stationary response. As a result, obtaining accurate modal parameter estimates from the analysis of the structural response only might be challenging, and the reliability of monitoring results must be carefully checked.

The present section deals with the application of automated OMA to a steel bridge, showing that reliable identification of the modal parameters is possible in the presence of transients due to impulsive traffic loading. Moreover, the influence of traffic, meant as an operational variable, on the results of continuous monitoring of the modal parameters is discussed considering relevant studies available in the technical literature.

While several studies have confirmed that modal parameters can be used as damage sensitive features for SHM applications, their effectiveness has long been debated because early applications were mostly based on periodic dynamic testing. As a result, the changes in the modal parameters were addressed to damage only, while the variability of the estimates due to environmental and operational variables (EOVs) was not considered. This makes the identification of damage from shifts in the selected damage indexes less obvious or even impossible if a continuous monitoring of damage sensitive features (and EOVs whenever possible) is not carried out. This circumstance solicited significant research efforts in recent years on the development of reliable and accurate techniques for the automated extraction of modal parameters $[15,16,19,20]$. However, while the results are not dependent on the operator skills, the lack of supervision in the modal parameter extraction process requires extensive testing of the available automated OMA procedures to check the reliability of results in different operating conditions. An extensive analysis of the performance of an automated OMA method based on simulated as well as experimental data is reported in [16]. In that context, a stationarity assumption was made, and the reliability of modal parameter estimates was jeopardized by large earthquake-induced transients [16,52]. Here, the same algorithm [16] is applied to the analysis of the vibration response of the "St. Francesco di Paola" steel revolving bridge in Taranto, which is the bridge that serves the base of the Italian Navy located in the Mar Piccolo (Figure 12a), in order to check the effectiveness of the automated OMA algorithm in the presence of some large and impulsive transients due to vehicle passages (Figure 12b).

The vibration response of the structure was recorded for a few hours, and the results of automated modal parameter monitoring (Figure 12c) have been compared with those obtained from the application of traditional (manual) OMA techniques. The average value and standard deviation of the automatically identified modal frequencies are reported in Table 8 together with the results of traditional OMA applied to a sample dataset; the comparison confirms the reliability and accuracy of the monitoring results even if they have been extracted under challenging conditions related to the specific structural scheme of the bridge (two nearby cantilevers) under impulsive loading due to the passage of buses and small trucks.

Figure 12c also shows that the natural frequencies of the fundamental modes exhibited some variations even in the short time window considered in this sample application. Those variations could be mainly addressed to traffic, the temperature being approximately constant over the considered (short) monitoring period.

The illustrated example confirms that traffic is one of the drivers of the natural frequency variability of bridges over time. Similar conclusions can be found in several studies in the literature [53-55]. Some of them have shown that the natural frequencies of short bridges are more sensitive to traffic with respect to those of medium- and long-span bridges, as a result of the mass ratio between the passing vehicles and the bridge [55,56]. However, monitoring the dynamic response of bridges under traffic conditions might be further complicated by the interaction with the passing vehicles [57] and by the simultaneous influence of other EOVs, such as temperature. Thus, given the complex interaction between EOVs and dynamic responses of individual bridges, their prevailing effects on modal properties must be compensated in order to enhance the sensitivity to damage of the selected feature and the reliability of SHM. 


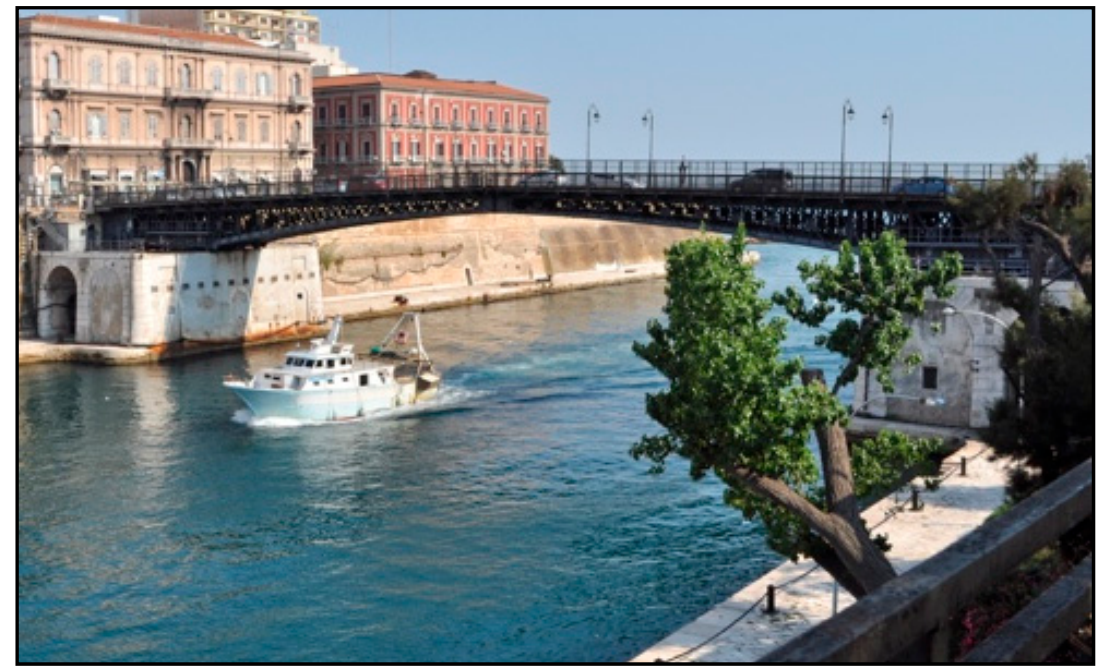

(a)

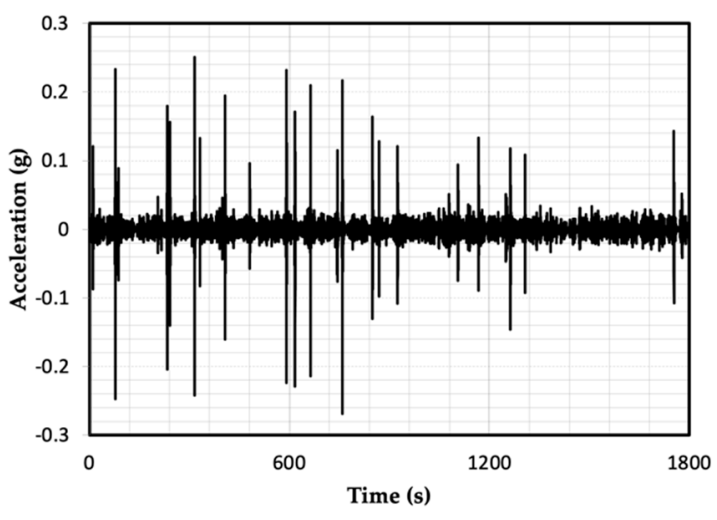

(b)

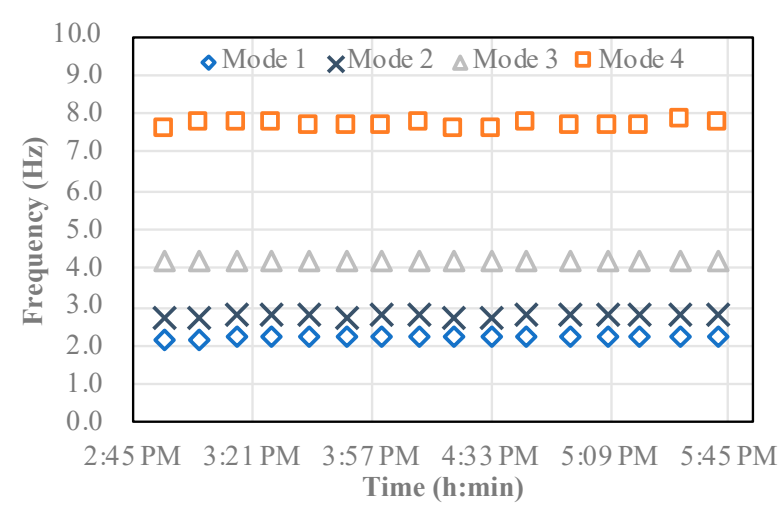

(c)

Figure 12. St. Francesco da Paola revolving bridge in Taranto (a), sample of the acceleration time histories (the early $30 \mathrm{~min}$ of the test) clearly showing the passage of heavy vehicles on the bridge-(b), tracking of the fundamental frequencies (c).

Table 8. St. Francesco da Paola revolving bridge: average value $\left(\mathrm{f}_{\mathrm{av}}\right)$ and standard deviation $\left(\sigma_{\mathrm{f}}\right)$ of the automatically identified natural frequencies in comparison with the result of traditional Operational Modal Analysis (OMA) applied to a sample dataset.

\begin{tabular}{ccc}
\hline Mode & $\begin{array}{c}\text { Traditional OMA } \\
\text { (Single Dataset) } \\
\mathbf{f}(\mathbf{H z})\end{array}$ & $\begin{array}{c}\text { Automated OMA } \\
\mathbf{( M u l t i p l e ~ D a t a s e t s )} \\
\mathbf{f}_{\mathbf{a v}}\left(\boldsymbol{\sigma}_{\mathbf{f}}\right)(\mathbf{H z})\end{array}$ \\
\hline 1 & 2.22 & $2.22(0.02)$ \\
2 & 2.70 & $2.77(0.03)$ \\
3 & 4.15 & $4.19(0.02)$ \\
4 & 7.77 & $7.70(0.07)$ \\
\hline
\end{tabular}

\subsection{Compensation of Environmental Effects}

A relevant disadvantage of modal-based SHM is definitely the sensitivity of natural frequency estimates to EOVs. Several studies have shown that EOV-induced changes in natural frequencies are often of the same order of magnitude as the damage-induced ones. If the influence of EOVs on modal parameters is not considered, false and missed identification errors may occur, thus jeopardizing the reliability of SHM. 
An effective compensation of the influence of EOVs on natural frequency estimates is therefore of paramount importance for a real application of the technique. Since modelling the effects of EOVs on the dynamic response of a structure is often very difficult, black-box models are preferred. They allow mapping the changes of the selected damage features against the explicit measurements of relevant EOVs [43,58-61], but the resulting model does not refer to physical laws and, as such, its usability is restricted to the structure on which it has been identified. In addition, defining which EOVs must be measured and where is often very challenging in the case of full-scale structures because of accessibility issues and the need for representative measurements of the EOVs $[42,62]$.

The temperature, for instance, is typically a key EOV that drives the dynamic response of the monitored structure. However, it is usually not uniformly distributed along the structure, and there might be differences with the temperature of air, or between the temperatures of indoor and outdoor surfaces, because of the solar radiation and thermal inertia [19,42,62]. Compensation methods not requiring explicit measurements of the EOVs $[19,63-65]$ are therefore particularly attractive, and several research efforts have been spent in their development in recent years.

This section summarizes relevant findings obtained from the application of SOBI [66] for compensation of the environmental and operational influences on the natural-frequency time series of a full-scale bridge without explicit measurements of the relevant EOVs.

The main assumption of the method is the existence of a linear relationship between the observed natural frequencies and the unmeasured EOVs (also called the sources). However, the mixing matrix determining the linear relationship is also unknown and determined from the data.

Figure 13a shows the Infante D. Henrique bridge in Portugal, which has been instrumented in order to continuously monitor its modal parameters by means of an automated algorithm [54]. Here, attention is paid to the fluctuations of the frequencies that are clearly shown in Figure 13b, and to the capacity of SOBI to predict such fluctuations and identify the associated potential sources. The application of the algorithm developed by the authors proved that three sources-Figure $13 \mathrm{c}-\mathrm{e}$ -were deemed to be relevant; indeed, they were able to describe more than $98 \%$ of the variability of the natural frequencies of the structure in healthy conditions; this circumstance is confirmed by the plot in Figure 13b, showing a good agreement between the experimental and the predicted values.

This result was consistent with a previous study [19], where up to three types of predictors (temperature, rms acceleration-associated to the traffic on the bridge, and damping) were considered. However, the model obtained from the application of SOBI was able to get better results in terms of prediction errors with respect to the regression models developed in [19]. Further investigations and analysis of the sources provided by SOBI allowed to recognize that, in addition to temperature (Figure 13c) and traffic (Figure 13e), humidity (Figure 13d) was the third relevant EOV affecting the natural frequency estimates.

The identification of the third environmental variable took advantage of the comparison between the estimated time series of the related source and data made available from a local weather station (Figure 13d). It is worth noting that only the temperature of the bridge was explicitly measured, while traffic was indirectly quantified through the rms values of acceleration.

These results demonstrate that SHM system can be implemented without any need for devices aimed at measuring physical parameters (temperature distribution, humidity and so on), provided that the variability of natural frequency estimates in operational conditions can be effectively predicted by the black-box model obtained by applying SOBI to the collected time series. Moreover, the reported results provide an original insight on the identification of the causes of the natural frequency variations in operational conditions and on the opportunity of differentiating environmental effects from damage. In fact, together with the possibility of developing accurate predictive models of the normal variability of natural frequencies, one of the major advantages of SOBI is its capacity to trace the patterns of the unknown EOVs, thus supporting their a-posteriori identification. The interested reader can refer to [66] for more details. 


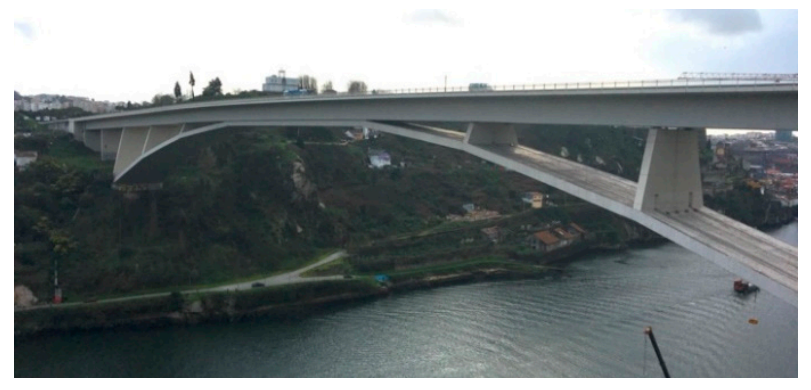

(a)

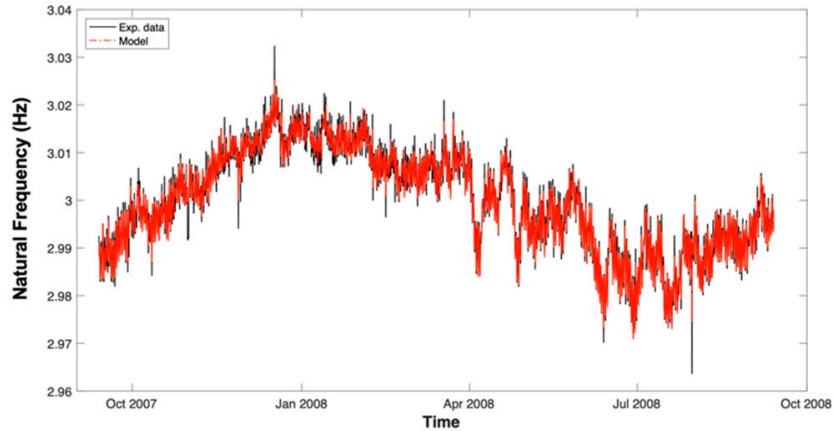

(b)

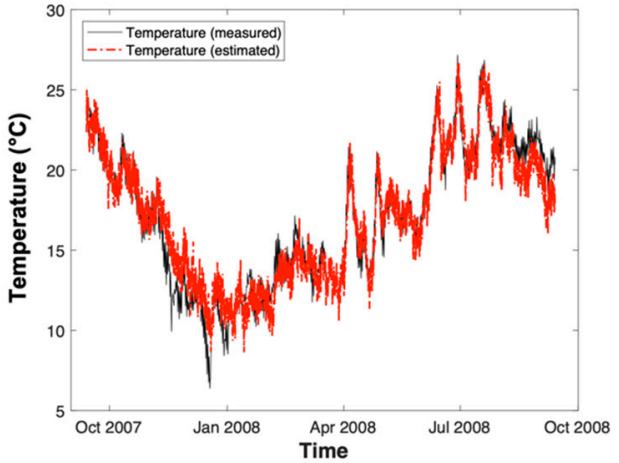

(c)

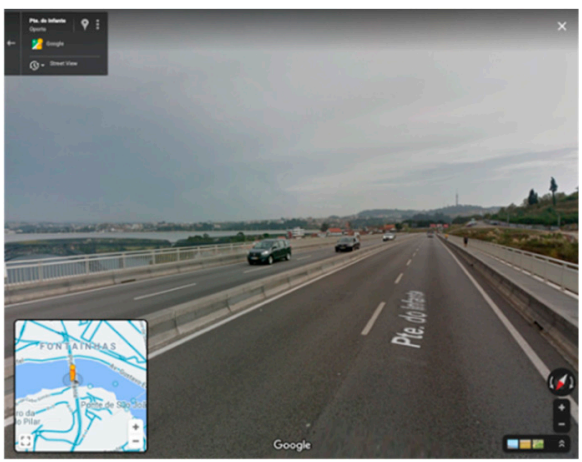

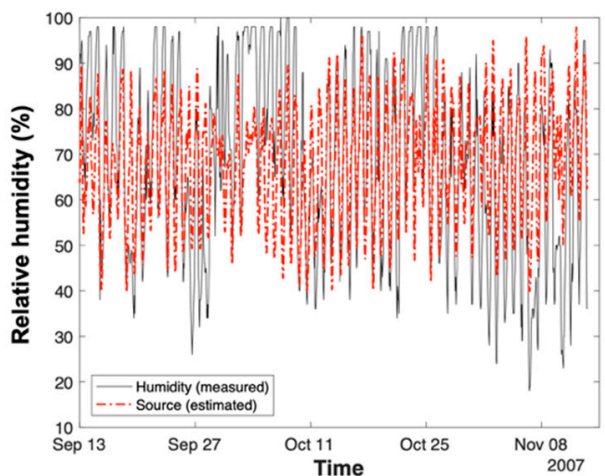

(d)

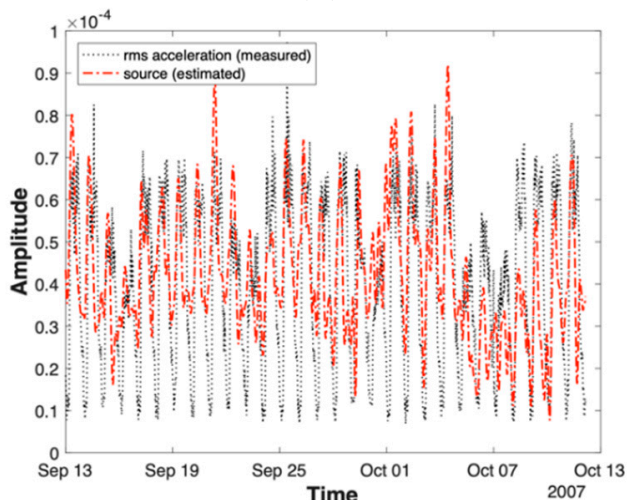

(e)

Figure 13. The Infante D. Henrique bridge (a); comparison between predicted and experimental bridge frequencies depending on time (b); patterns of relevant environmental and operational variables (EOVs) estimated by Second Order Blind Identification (SOBI): temperature (c), humidity (d), and traffic (e). 


\section{Summary and Final Remarks}

The paper reports several experiences made by the authors in the field of dynamic identification of bridge structures over the years. They were selected in order to point out the capability of vibration-based techniques and particularly of OMA in supporting the design, erection, commissioning and management of bridge structures. The analyzed case studies confirm the feasibility of data-driven approaches based on the application of advanced OMA techniques in enhancing the knowledge on the dynamic behavior of existing bridges and assess their health state through continuous monitoring. In particular, the use of OMA for FE model validation, the formulation of predictive correlations for the estimation of the fundamental frequency of RC arch bridges, and for vibration serviceability assessment of pedestrian bridges has been discussed. Moreover, applications of automated OMA procedures for the continuous monitoring of fundamental modal parameters and structural health assessments have been reviewed, remarking the attractiveness of this technology for the applications to full-scale bridges. The illustrated experiences remarked the potential of modal-based damage detection as a global method for structural health assessments; moreover, they revealed the possibility to achieve reliable results from the continuous modal-based SHM of bridges even in the presence of transients due to traffic and significant influence of EOVs on modal property estimates.

Author Contributions: Conceptualization, C.R. and G.F.; methodology, C.R.; software, C.R.; validation, C.R. and G.F.; formal analysis, C.R.; investigation, C.R.; resources, M.A.N.; data curation, M.A.N.; writing-original draft preparation, C.R.; writing-review and editing, C.R., M.A.N. and G.F.; visualization, C.R. and G.F.; supervision, C.R., M.A.N. and G.F.; project administration, C.R., M.A.N. All authors have read and agreed to the published version of the manuscript.

Funding: This research received no external funding.

Acknowledgments: The authors would like to thank all the engineers of the S2X team (www.s2x.it) who contributed to most of the experimental tests and applications described in the present paper. The authors are grateful to Prof. Giuseppe Carlo Marano and to the Italian Navy, Taranto Headquarters, for the opportunity offered to perform the experimental tests on the S. Francesco Revolving Bridge. Regarding the tests on the Ufita bridge, the authors express their gratitude to Prof. M.R. Pecce, University of Sannio, who coordinated most of the activities on the bridge in the context of the PON 2007-2013 "STRIT" research project.

Conflicts of Interest: The authors declare no conflict of interest.

\section{References}

1. Rainieri, C.; Fabbrocino, G. Operational Modal Analysis of Civil Engineering Structures: An Introduction and Guide for Applications; Springer: New York, NY, USA, 2014.

2. Magalhaes, F.; Cunha, A. Explaining operational modal analysis with data from an arch bridge. Mech. Syst. Signal. Process. 2011, 25, 1431-1450. [CrossRef]

3. Reynders, E.; De Roeck, G. Reference-based combined deterministic-stochastic subspace identification for experimental and operational modal analysis. Mech. Syst. Signal. Process. 2008, 22, 617-637. [CrossRef]

4. Magalhaes, F.; Cunha, A.; Caetano, E.; Brincker, R. Damping estimation using free decays and ambient vibration tests. Mech. Syst. Signal. Process. 2010, 24, 1274-1290. [CrossRef]

5. Cunha, A.; Caetano, E.; Calcada, R.; De Roeck, G.; Peeters, B. Dynamic Measurements on Bridges. Design, Rehabilitation and Monitoring. Bridge Eng. 2003, 156, 135-148. [CrossRef]

6. Brownjohn, J.M.W.; Moyo, P.; Omenzetter, P.; Lu, Y. Assessment of highway bridge upgrading by dynamic testing and finite-element model updating. J. Bridge Eng. 2003, 8, 162-172. [CrossRef]

7. Ministero delle Infrastrutture e dei Trasporti-Consiglio Superiore dei Lavori Pubblici. Circolare $n .7$ del 21/01/2019-Istruzioni per l'applicazione dell' «Aggiornamento delle "Norme tecniche per le costruzioni"» di cui al decreto ministeriale 17 gennaio 2018; Ministero delle Infrastrutture e dei Trasporti: Rome, Italy, 2019. (In Italian)

8. Caetano, E.; Cunha, A.; Magalhaes, F.; Moutinho, C. Studies for controlling human-induced vibration of the Pedro e Ines footbridge, Portugal. Part 1: Assessment of dynamic behaviour. Eng. Struct. 2010, 32, 1069-1081. [CrossRef] 
9. Caetano, E.; Cunha, A.; Moutinho, C.; Magalhaes, F. Studies for controlling human-induced vibration of the Pedro e Ines footbridge, Portugal. Part 2: Implementation of tuned mass dampers. Eng. Struct. 2010, 32, 1082-1091. [CrossRef]

10. Van Nimmen, K.; Lombaert, G.; De Roeck, G.; Van den Broeck, P. Vibration serviceability of footbridges: Evaluation of the current codes of practice. Eng. Struct. 2014, 59, 448-461. [CrossRef]

11. Saidou Sanda, M.; Gauron, O.; Turcotte, N.; Lamarche, C.-P.; Paultre, P.; Talbot, M.; Laflamme, J.-F. Efficient finite elements model updating for damage detection in bridges. In Proceedings of the 7th International Conference on Experimental Vibration Analysis for Civil Engineering Structures, San Diego, CA, USA, 12-14 July 2017; pp. 293-305.

12. Teughels, A.; De Roeck, G. Structural damage identification of the highway bridge Z24 by FE model updating. J. Sound Vib. 2004, 278, 589-610. [CrossRef]

13. Scozzese, F.; Ragni, L.; Tubaldi, E.; Gara, F. Modal properties variation and collapse assessment of masonry arch bridges under scour action. Eng. Struct. 2019, 199, 109665. [CrossRef]

14. Ministero delle Infrastrutture e dei Trasporti-Consiglio Superiore dei Lavori Pubblici. Linee guida per la classificazione e gestione del rischio, la valutazione della sicurezza ed il monitoraggio dei ponti esistenti; Ministero delle Infrastrutture e dei Trasporti: Rome, Italy, 2020.

15. Rainieri, C.; Fabbrocino, G. Automated output-only dynamic identification of civil engineering structures. Mech. Syst. Signal. Process. 2010, 24, 678-695. [CrossRef]

16. Rainieri, C.; Fabbrocino, G. Development and validation of an automated operational modal analysis algorithm for vibration-based monitoring and tensile load estimation. Mech. Syst. Signal. Process. 2015, 60-61, 512-534. [CrossRef]

17. Marques, F.; Cunha, A.; Caetano, E.; Moutinho, C.; Magalhaes, F. Analysis of dynamic and fatigue effects in an old metallic riveted bridge. J. Constr. Steel Res. 2014, 99, 85-101. [CrossRef]

18. UNI Ente Italiano di Normazione. UNI/TR 11634-Linee Guida per il monitoraggio strutturale/Guidelines for Structural Health Monitoring; Ente Italiano di Normazione: Milan, Italy, 2016.

19. Magalhaes, F.; Cunha, A.; Caetano, E. Vibration based structural health monitoring of an arch bridge: From automated OMA to damage detection. Mech. Syst. Signal. Process. 2012, 28, 212-228. [CrossRef]

20. Gentile, C.; Saisi, A. Continuous dynamic monitoring of a centenary iron bridge for structural modification assessment. Front. Struct. Civ. Eng. 2014, 9, 26-41. [CrossRef]

21. Herlufsen, H.; Andersen, P.; Gade, S.; Møller, N. Identification techniques for Operational Modal Analysis-An overview and practical experiences. In Proceedings of the 1st International Operational Modal Analysis Conference, Copenhagen, Denmark, 26-27 April 2005.

22. Brincker, R.; Zhang, L.; Andersen, P. Modal identification of output-only systems using frequency domain decomposition. Smart Mater. Struct. 2001, 10, 441-445. [CrossRef]

23. Van Overschee, P.; De Moor, B. Subspace Identification for Linear Systems: Theory-Implementation-Applications; Kluwer Academic Publishers: Dordrecht, The Netherlands, 1996.

24. Jacobsen, N.-J.; Andersen, P.; Brincker, R. Applications of frequency domain curve-fitting in the EFDD technique. In Proceedings of the 26th International Modal Analysis Conference, Orlando, FL, USA, 4-7 February 2008.

25. Peeters, B.; Van der Auweraer, H. PolyMAX: A revolution in operational modal analysis. In Proceedings of the 1st International Operational Modal Analysis Conference, Copenhagen, Denmark, 26-27 April 2005.

26. Rainieri, C. Perspectives of Second-Order Blind Identification for Operational Modal Analysis of civil structures. Shock Vib. 2014, 2014. [CrossRef]

27. Benedettini, F.; Zulli, D.; Alaggio, R. Frequency-veering and mode hybridization in arch bridges. In Proceedings of the XXVII International Modal Analysis Conference, Orlando, FL, USA, 9-12 February 2009.

28. Benedettini, F.; Alaggio, R.; Manetta, P. Arch bridges in Provincia di Teramo: Tests, identification and numerical models. In Proceedings of the 1st International Operational Modal Analysis Conference, Copenhagen, Denmark, 26-27 April 2005.

29. Bayraktar, A.; Turker, T.; Altunisik, A.C. Experimental frequencies and damping ratios for historical masonry arch bridges. Constr. Build. Mater. 2015, 75, 234-241. [CrossRef]

30. Ubertini, F.; Materazzi, A.L.; Gentile, C.; Pelliccia, F. Automatic identification of modal parameters: Application to a reinforced concrete arch bridge. In Proceedings of the 5th European Conference on Structural Control, Genoa, Italy, 18-20 June 2012. 
31. Marrongelli, G.; Magalhaes, F.; Cunha, A. Automated Operational Modal Analysis of an arch bridge considering the influence of the parametric methods inputs. Procedia Eng. 2017, 199, 2172-2177. [CrossRef]

32. Computers \& Structures, Inc. CSI Analysis Reference Manual for SAP2000 ${ }^{\circledR} ;$ ETABS®, SAFE® and CSiBridge®: Walnut Creek, CA, USA, 2017.

33. Pecce, M.R.; Ielardi, A.; Fabbrocino, G.; Rainieri, C. Modellazione dinamica e analisi modale operazionale di un ponte composto. In Proceedings of the Atti XXV Congresso Collegio dei Tecnici dell'Acciaio (CTA 2015), Salerno, Italy, 1-3 October 2015. (In Italian)

34. Rainieri, C.; Fabbrocino, G. Influence of model order and number of block rows on accuracy and precision of modal parameter estimates in stochastic subspace identification. Int. J. Lifecycle Perform. Eng. 2014, 1, 317-334. [CrossRef]

35. Živanovicć, S.; Pavicć, A.; Reynolds, P. Vibration serviceability of footbridges under human-induced excitation: A literature review. J. Sound Vib. 2005, 279, 1-74. [CrossRef]

36. Cuevas, R.G.; Jimenez-Alonso, J.F.; Martinez, F.; Diaz, I.M. Assessment of the Lateral Vibration Serviceability Limit State of Slender Footbridges Including the Postlock-in Behaviour. Appl. Sci. 2020, 10, 967. [CrossRef]

37. HIVOSS. Floor Vibrations-Human Induced Vibrations of Steel Structures. Design of Footbridges Guideline, RFS2-CT-2007-00033; Publications Office of the European Union: Luxembourg, UK, 2008.

38. BSI - British Standards Institutions. UK National Annex to Eurocode 1: Actions on Structures-Part 2: Traffic Loads on Bridges, BS NAEN; 1991-2; BSI: London, UK, 2004.

39. SETRA-The Technical Department for Transports, Roads and Bridges Engineering and Road Safety. Assessment of Vibrational Behavior of Footbridges under Pedestrian Loading; Technical Guide SETRA: Paris, France, 2006.

40. Bendat, J.S.; Piersol, A.G. Random Data: Analysis and Measurement Procedures; John Wiley \& Sons: New York, NY, USA, 1986.

41. Farrar, C.R.; Worden, K. Structural Health Monitoring: A Machine Learning Perspective; John Wiley and Sons Ltd.: Chichester, UK, 2012.

42. Ubertini, F.; Comanducci, G.; Cavalagli, N.; Pisello, A.L.; Materazzi, A.L.; Cotana, F. Environmental effects on natural frequencies of the San Pietro bell tower in Perugia, Italy, and their removal for structural performance assessment. Mech. Syst. Signal. Process. 2017, 82, 307-322. [CrossRef]

43. Cross, E.J.; Koo, K.Y.; Brownjohn, J.M.W.; Worden, K. Long-term monitoring and data analysis of the Tamar Bridge. Mech. Syst. Signal. Process. 2013, 35, 16-34. [CrossRef]

44. Mustafa, S.; Matsumoto, Y.; Yamaguchi, H. Vibration-Based Health Monitoring of an Existing Truss Bridge Using Energy-Based Damping Evaluation. J. Bridge Eng. 2018, 23, 04017114. [CrossRef]

45. Allemang, R.J.; Brown, D.L. A Correlation Coefficient for Modal Vector Analysis. In Proceedings of the 1st International Modal Analysis Conference, Orlando, FL, USA, 8-10 November 1982; pp. 110-116.

46. Lieven, N.A.J.; Ewins, D.J. Spatial Correlation of Mode Shapes, The Coordinate Modal Assurance Criterion (COMAC). In Proceedings of the 6th International Modal Analysis Conference, Kissimmee, FL, USA, 1-4 February 1988; pp. 690-695.

47. Pandey, A.; Biswas, M.; Samman, M. Damage detection from changes in curvature mode shapes. J. Sound Vib. 1991, 145, 321-332. [CrossRef]

48. Stubbs, N.; Kim, J.T.; Topole, K. An efficient and robust algorithm for damage localization in offshore platforms. In Proceedings of the ASCE Tenth Structures Congress, San Antonio, TX, USA, 13-15 April 1992; pp. 543-546.

49. Pandey, A.; Biswas, M. Damage detection in structures using changes in flexibility. J. Sound Vib. 1994, 169, 3-17. [CrossRef]

50. Limongelli, M.P. The interpolation damage detection method for frames under seismic excitation. J. Sound Vib. 2011, 330, 5474-5489. [CrossRef]

51. Limongelli, M.P.; Giordano, P.F. Vibration-based damage indicators: A comparison based on information entropy. J. Civ. Struct. Health Monit. 2020, 10, 251-266. [CrossRef]

52. Rainieri, C.; Gargaro, D.; Fabbrocino, G.; Maddaloni, G.; Di Sarno, L.; Prota, A.; Manfredi, G. Shaking table tests for the experimental verification of the effectiveness of an automated modal parameter monitoring system for existing bridges in seismic areas. Struct. Control. Health Monit. 2018, 25. [CrossRef]

53. Soyoz, S.; Feng, M.Q. Long-term monitoring and identification of bridge structural parameters. Comput. Aided Civ. Infrastruct. Eng. 2008, 24, 82-92. [CrossRef] 
54. Magalhaes, F.; Cunha, A.; Caetano, E. Online automatic identification of the modal parameters of a long span arch bridge. Mech. Syst. Signal. Process. 2009, 23, 316-329. [CrossRef]

55. De Roeck, G.; Maeck, J.; Michielsen, T.; Seynaeve, E. Traffic-induced shifts in modal properties of bridges. Proc. SPIE Int. Soc. Opt. Eng. 2002, 4753, 630-636.

56. Sohn, H. Effects of environmental and operational variability on structural health monitoring. Philos. Trans. R. Soc. A 2007, 365, 539-560. [CrossRef]

57. Brady, S.P.; O' Brien, E.J.; Znidaric, A. Effect of Vehicle Velocity on the Dynamic Amplification of a Vehicle Crossing a Simply Supported Bridge. J. Bridge Eng. 2006, 11, 241-249. [CrossRef]

58. Peeters, B.; Maeck, J.; De Roeck, G. Vibration-based damage detection in civil engineering: Excitation sources and temperature effects. Smart Mater. Struct. 2001, 10, 518-527. [CrossRef]

59. Ni, Y.; Hua, X.; Fan, K.; Ko, J. Correlating modal properties with temperature using long-term monitoring data and support vector machine technique. Eng. Struct. 2005, 27, 1762-1773. [CrossRef]

60. Sohn, H.; Dzwonczyk, M.; Straser, E.; Law, K.; Meng, T.; Kiremidjian, A. Adaptive modeling of environmental effects in modal parameters for damage detection in civil structures. Proc. SPIE Int. Soc. Opt. Eng. 1998, $3325,127-138$.

61. Ni, Y.; Zhou, H.; Ko, J. Generalization capability of neural network models for temperature-frequency correlation using monitoring data. J. Struct. Eng. 2009, 135, 1290-1300. [CrossRef]

62. Zhou, H.F.; Ni, Y.Q.; Ko, J.M. Constructing input to neural networks for modeling temperature-caused modal variability: Mean temperatures, effective temperatures, and principal components of temperatures. Eng. Struct. 2010, 32, 1747-1759. [CrossRef]

63. Deraemaeker, A.; Reynders, E.; De Roeck, G.; Kullaa, J. Vibration-based structural health monitoring using output-only measurements under changing environment. Mech. Syst. Signal. Process. 2008, 22, 34-56. [CrossRef]

64. Yan, A.-M.; Kerschen, G.; De Boe, P.; Golinval, J.-C. Structural damage diagnosis under varying environmental conditions-Part I: A linear analysis. Mech. Syst. Signal. Process. 2005, 19, 847-864. [CrossRef]

65. Reynders, E.; Wursten, G.; De Roeck, G. Output-only structural health monitoring in changing environmental conditions by means of nonlinear system identification. Struct. Health Monit. 2014, 13, 82-93. [CrossRef]

66. Rainieri, C.; Magalhaes, F.; Gargaro, D.; Fabbrocino, G.; Cunha, A. Predicting the variability of natural frequencies and its causes by Second-Order Blind Identification. Struct. Health Monit. 2019, 18, 486-507. [CrossRef]

Publisher's Note: MDPI stays neutral with regard to jurisdictional claims in published maps and institutional affiliations.

(C) 2020 by the authors. Licensee MDPI, Basel, Switzerland. This article is an open access article distributed under the terms and conditions of the Creative Commons Attribution (CC BY) license (http://creativecommons.org/licenses/by/4.0/). 